\title{
User's Guide to the NIST Virtual Cement and Concrete Testing Laboratory. Version 1.0
}

Dale P. Bentz
Glenn P. Forney

Goal: To reduce the number of physical concrete tests and expedite the R\&D process
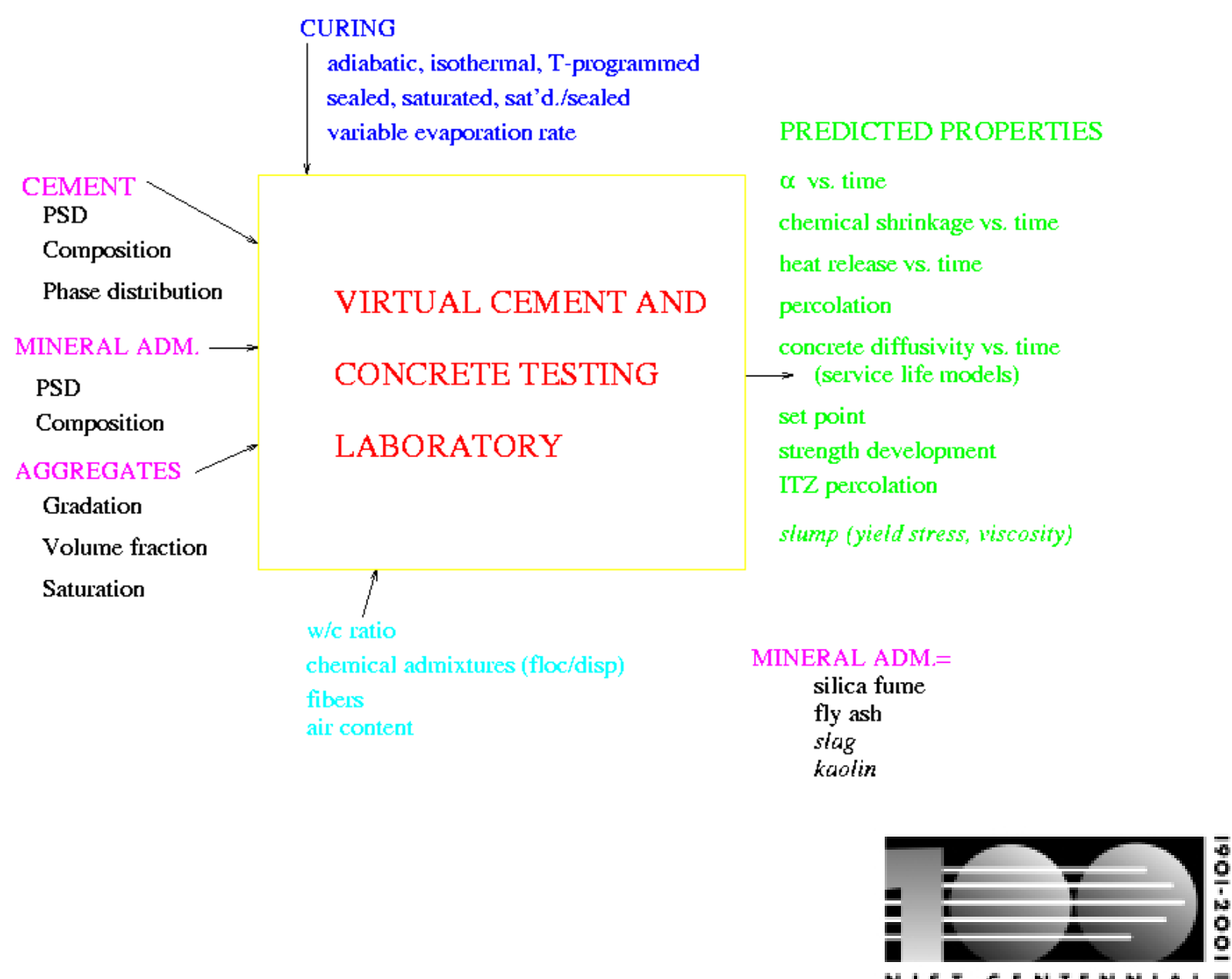

NISTCENTEN NIAL

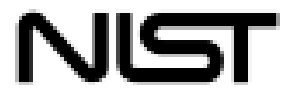

National Institute of Standards and Technology Technology Administration, U.S. Department of Commerce 


\section{User's Guide to the NIST Virtual Cement and Concrete Testing Laboratory. Version 1.0}

Dale P. Bentz and Glenn P. Forney Building and Fire Research Laboratory

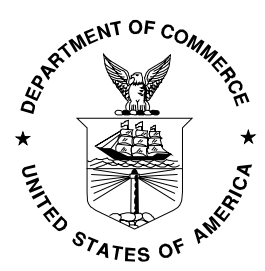

U.S. Department of Commerce Norman Y. Mineta, Secretary

Technology Administration Dr. Cheryl L. Shavers, Under Secretary of Commerce for Technology 


\title{
NISTIR 6583
}

User's Guide to the Virtual Cement and Concrete Testing Laboratory. Version 1.0

Dale P. Bentz and Glenn P. Forney

Building and Fire Research Laboratory

National Institute of Standards and Technology

Gaithersburg, MD 20899-8621

\begin{abstract}
This NISTIR serves as the user's manual for Version 1.0 of the Virtual Cement and Concrete Testing Laboratory (VCCTL). Using the VCCTL, a user may create starting microstructures of cement (gypsum, fly ash, etc.) particles in water, hydrate the microstructures under controlled curing conditions, leach the portlandite and remaining cement clinker phases from hydrated microstructures, view images and animations of 3-D microstructures, and/or evaluate a variety of properties of hydrated/leached microstructures for direct comparison to experimental data. The VCCTL includes a web-based interface that provides a menu-driven system of forms for obtaining user input and returning results. Two example applications of using the VCCTL to study specific scenarios of interest to the cement-based materials research community are also presented.
\end{abstract}

Keywords: Building technology, cement hydration, computer modeling, concrete testing, microstructure, simulation, virtual laboratory. 


\section{Contents}

$\begin{array}{lll}\text { Abstract } & \text { iii }\end{array}$

List of Figures

1 Introduction $\quad 1$

2 Descriptions of Menu Selections $\quad 1$

2.1 Menu Selection 0) Access the User's Guide for the VCCTL . . . . . . . . . . . . . . . . 3

2.2 Menu Selection 1) Enter the cement images database system . . . . . . . . . . . . 3

2.3 Menu Selection 2) Create a particle size distribution file . . . . . . . . . . . . . . 7

2.4 Menu Selection 3) Generate an initial 3-D microstructure . . . . . . . . . . . . . . . . . 9

2.5 Menu Selection 4) View a 2-D slice from any 3-D microstructure . . . . . . . . . . . . . . 13

2.6 Menu Selection 5) Generate an animation from any 3-D microstructure . . . . . . . . . 13

2.7 Menu Selection 6) View an animation from any 3-D microstructure . . . . . . . . . . . . . 13

2.8 Menu Selection 7) Distribute all phases amongst cement particles . . . . . . . . . . . . . 13

2.9 Menu Selection 8) Filter a 3-D microstructure to distribute only two phases amongst cement

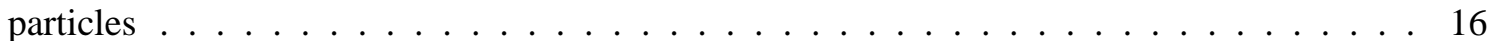

2.10 Menu Selection 9) Compute spatial statistics for a 3-D microstructure $\ldots \ldots \ldots$. . . . . 18

2.11 Menu Selection 10) Sinter a 3-D microstructure to adjust the hydraulic radius of one phase . 20

2.12 Menu Selection 11) Distribute fly ash phases amongst fly ash particles . . . . . . . . . . . . 22

2.13 Menu Selection 12) Input a temperature history (curing) file . . . . . . . . . . . . . . . 24

2.14 Menu Selection 13) Hydrate a 3-D microstructure . . . . . . . . . . . . . . . . . . 25

2.15 Menu Selection 14) Measure phase fractions vs. distance from aggregate . . . . . . . . . . 30

2.16 Menu Selection 15) Leach CH/cement from a hydrated microstructure . . . . . . . . . . . 30

2.17 Menu Selection 16) Evaluate percolation properties of a hydrated/leached microstructure . . 32

2.18 Menu Selection 17) Plot predicted properties (vs. experimental data) . . . . . . . . . . . . 32

2.19 Menu Selection 18) Predict chloride ion diffusivity of a concrete based on mixture parameters 35

$3 \quad$ Example Applications of the VCCTL 37

3.1 Replacement of Coarse Cement Particles by Inert Fillers _ . . . . . . . . . . . . 37

3.2 Seeding of the Hydration with Fine $C-S-H$ particles $\ldots \ldots \ldots$. . . . . . . . . 46

$\begin{array}{llr}4 & \text { Summary } & 48\end{array}$

5 Acknowledgements $\quad 48$ 


\section{List of Figures}

1 Main menu for the Virtual Cement and Concrete Testing Laboratory. . . . . . . . . . . . . 2

2 Form to select a cement from the cement images database. . . . . . . . . . . . . . 4

3 First half of page from cements image database for Cement 135. . . . . . . . . . 5

4 Second half of page from cements image database for Cement 135 . . . . . . . . . 6

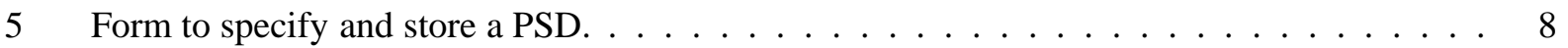

6 Form to create a starting 3-D particle microstructure. . . . . . . . . . . . . . . 10

7 Form to create a starting 3-D particle microstructure (continued) . . . . . . . . . . . 11

8 Form to create a starting 3-D particle microstructure (continued). . . . . . . . . . . . . 12

9 Form to specify inputs to be used in distributing phases amongst cement particles. . . . . . 15

10 Form to specify inputs to be used in filtering a 3-D microstructure. . . . . . . . . . . . . 17

11 Results from spatial statistics analysis of an initial 3-D microstructure. . . . . . . . . . . . 19

12 Form to specify inputs to be used in "sintering" a 3-D microstructure. . . . . . . . . . . 21

13 Form to specify inputs to be used in distributing the phases amongst the fly ash particles. . . 23

14 Form to specify the temperature history to be used in curing a microstructure during hydration. 24

15 Form to hydrate a starting 3-D microstructure. . . . . . . . . . . . . . . . 27

16 Form to hydrate a starting 3-D microstructure (continued). . . . . . . . . . . . 28

17 Form to hydrate a starting 3-D microstructure (continued). . . . . . . . . . . . . . . . . 29

18 Form to specify inputs for leaching $\mathrm{CH} /$ cement from a hydrated 3-D microstructure. . . . . . 31

19 Results for percolation of capillary porosity in microstructure cem133wc030n1f.img. . . . . 32

20 Form for selecting files to plot or for which to enter experimental data. . . . . . . . . . 33

21 Example of results available for plotting via Menu Selection 17. . . . . . . . . . . . 34

22 Form to specify inputs for predicting chloride ion diffusivity of a concrete based on mixture

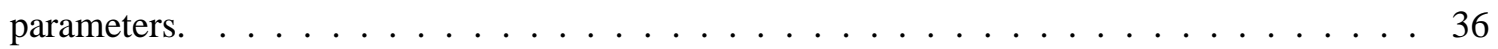

23 2-D slice from 3-D starting microstructure for Cement 135 , w/c=0.25, with no cement replacement by inert fillers. . . . . . . . . . . . . . . . 38

24 2-D slice from 3-D starting microstructure for Cement 135 , w/c=0.25, with $30.8 \%$ cement replacement by inert fillers. . . . . . . . . . . . . . . . . . . 39

25 2-D slice from 3-D hydrated microstructure for Cement $135, \mathrm{w} / \mathrm{c}=0.25$, with no cement replacement by inert fillers. . . . . . . . . . . . . . . . . .

26 2-D slice from 3-D hydrated microstructure for Cement 135 , w/c $=0.25$, with $30.8 \%$ cement replacement by inert fillers. . . . . . . . . . . . . . . . . . .

27 Predicted degree of hydration and compressive strength development for base $\mathrm{w} / \mathrm{c}=0.25$ system and system with coarsest $20.5 \%$ of cement particles replaced by inert filler. Solid line is original system and dotted line is system with $20.5 \%$ replacement. . . . . . . . . . . .

28 Predicted degree of hydration and compressive strength development for base $\mathrm{w} / \mathrm{c}=0.25$ system and system with coarsest $30.8 \%$ of cement particles replaced by inert filler. Solid line is original system and dotted line is system with $30.8 \%$ replacement. . . . . . . . . . .

29 Predicted reduction in compressive strength due to coarse cement particle replacement for Cement 135 with w/s=0.25. Solid line is reduction with $20.5 \%$ replacement level and dotted line is reduction with replacement level of $30.8 \% \ldots \ldots \ldots \ldots$. . . . . . . . . . . 45

30 Predicted increase in hydration and compressive strength due to "seeding" microstructure with $1 \mu \mathrm{m} C-S-H$ particles. . . . . . . . . . . . . . . . . . . . 47 


\section{Introduction}

This user's manual provides guidance for using Version 1.0 of the NIST Virtual Cement and Concrete Testing Laboratory (VCCTL). This virtual laboratory consists of a web-based interface and underlying computer models and programs that allow the user to create, hydrate, degrade, and evaluate 3-D cement-based microstructures from their desktop computer. Thus, the VCCTL should serve the cement and concrete research and development community, ultimately reducing the number of costly physical concrete tests needed, while also allowing the rapid analysis of a wide variety of "what if" type scenarios.

The main underlying program for the VCCTL (CEMHYD3D) has been described previously [1], as well as numerous applications based on using the underlying models [2-7]. This user's manual therefore provides a detailed description of the web-based user interface and a few examples of using the VCCTL to investigate specific problems of interest to the cement and concrete research community. The VCCTL is available online at http://vcctl.cbt.nist.gov. It is suggested that the user be connected to this web site as they read this user's manual in order to help clarify the forms, the inputs needed, and the results produced for the various menu selections.

\section{DISCLAIMER}

This software was developed at the National Institute of Standards and Technology by employees of the Federal Government in the course of their official duties. Pursuant to title 17 Section 105 of the United States Code this software is not subject to copyright protection and is in the public domain. The VCCTL is an experimental system. NIST assumes no responsibility whatsoever for its use by other parties, and makes no guarantees, expressed or implied, about its quality, reliability, or any other characteristic. We would appreciate acknowledgement if the software is used.

The U.S. Department of Commerce makes no warranty, expressed or implied, to users of the VCCTL and associated computer programs, and accepts no responsibility for its use. Users of the VCCTL assume sole responsibility under Federal law for determining the appropriateness of its use in any particular application; for any conclusions drawn from the results of its use; and for any actions taken or not taken as a result of analyses performed using these tools.

Users are warned that the VCCTL is intended for use only by those competent in the field of cementbased materials and is intended only to supplement the informed judgment of the qualified user. The software package contains computer models which may or may not have predictive value when applied to a specific set of factual circumstances. Lack of accurate predictions by the models could lead to erroneous conclusions with regard to materials selection and design. All results should be evaluated by an informed user.

\section{INTENT AND USE}

The algorithms, procedures, and computer programs described in this report constitute a prototype system for a virtual laboratory for the testing of cement and concrete. They have been compiled from the best knowledge and understanding currently available, but have important limitations that must be understood and considered by the user. The VCCTL system is intended for use by persons competent in the field of cement-based materials and with some familiarity with computers. It is intended as an aid in the materials selection, optimization, and design process.

\section{Descriptions of Menu Selections}

Upon entering the VCCTL system, the main menu shown in Figure 1 is displayed. Each of the possible main menu selections will be discussed in the subsections which follow. 


\section{Main Menu for Virtual Cement and Concrete Testing Laboratory}

Please select from the following menu:

0) Access the User's Guide for the VCCTL

1) Enter the cement images database system

2) Create a particle size distribution file

3) Generate an initial 3-D microstructure

4) View a 2-D slice from any 3-D microstructure

5) Generate an animation from any 3-D microstructure

6) View an animation from any 3-D microstructure

7) Distribute all phases amongst cement particles

8) Filter a 3-D microstructure to distribute only two phases amongst cement particles

9) Compute spatial statistics for a 3-D microstructure

10) Sinter a 3-D microstructure to adjust the hydraulic radius of one phase

11) Distribute fly ash phases amongst fly ash particles

12) Input a temperature history (curing) file

13) Hydrate a 3-D microstructure

14) Measure phase fractions vs. distance from aggregate

15) Leach $\mathrm{CH} /$ cement from a hydrated microstructure

16) Evaluate percolation properties of a hydrated/leached microstructure

17) Plot predicted properties (vs. experimental data)

18) Predict chloride ion diffusivity of a concrete based on mixture parameters 


\subsection{Menu Selection 0) Access the User's Guide for the VCCTL}

Menu Selection 0 simply provides a link to the HTML version of this user's guide available online as part of the VCCTL system.

\subsection{Menu Selection 1) Enter the cement images database system}

For users of the VCCTL who do not have access to a scanning electron microscope (SEM) with X-ray imaging capabilities, a database of cement images has been created. Currently, the database contains 2-D images, quantitative image analysis results, and measured particle size distributions (PSDs) for 17 different cements produced in four different countries, as shown in Figure 2. The characterization process has been described in detail for two of the Cement and Concrete Reference Laboratory cements in a previously published report [6]. As new cements are processed at NIST, they will be added to the existing database. Typically, the PSD and quantitiative phase analysis information will be used as input to construct a starting 3-D microstructure for a specific cement.

Upon entering the cement images database, the user will first be allowed to select a specific cement of interest using a fill-in form. Once this form is submitted, a 2-D color processed SEM/X-ray image will be returned along with the measured PSD for the chosen cement, as shown in Figures 3 and 4 for Cement 135, issued by the Cement and Concrete Reference Laboratory in January of 2000. The PSD is reported on a particle diameter basis, with both mass and number fractions reported. The number fractions have been obtained from the mass fractions based on the number of pixel elements present in digitized 3-D particles of each specific diameter [1]. For small diameters (3 pixels and 5 pixels), it should be noted that the volume of the digitized sphere is significantly greater than an equivalent diameter continuum sphere.

Each cement page also contains two links to further information. The About this cement link directs the user to a secondary page that contains the quantitative image analysis results for this cement, including the names of the computed correlation files which can be used to create "equivalent" 3-D microstructures. Normally, this page will be printed by the user for later use with Menu Selection 7 to distribute the cement phases amongst the 3-D particles. The Access the ftp site for these files link directs the user to an anonymous ftp site from which the correlation and PSD files can be downloaded for personal use. Optionally, the measured PSD provided on the cement page can be printed and typed in by the user as input into Menu Selection 2) Create a particle size distribution file. 


\section{Cement Images and PSDs Available for Microstructure Modeling}

\section{Please select one of the portland cements below to view image and PSD info (then press the submit button at the bottom of the page).}

CCRL Cement 115 (Jan. 1995)

CCRL Cement 116 (Jan. 1995)

CCRL Cement 133 (June 1999)

CCRL Cement 135 (Jan. 2000)

CCRL Cement 136 (Jan. 2000)

Montalieu Cement (French)

South African Cement

Dyckerhoff Cement $654 \mathrm{~m}^{2} / \mathrm{kg}$ (Germany) Dyckerhoff Cement $541 \mathrm{~m}^{2} / \mathrm{kg}$ (Germany)

Dyckerhoff Cement $370 \mathrm{~m}^{2} / \mathrm{kg}$ (Germany) Dyckerhoff Cement 279 m²/kg (Germany)

Dyckerhoff Cement $197 \mathrm{~m}^{2} / \mathrm{kg}$ (Germany)

Dyckerhoff Cement $608 \mathrm{~m}^{2} / \mathrm{kg}$ (Germany) Dyckerhoff Cement $468 \mathrm{~m}^{2} / \mathrm{kg}$ (Germany)

Dyckerhoff Cement $357 \mathrm{~m}^{2} / \mathrm{kg}$ (Germany) Dyckerhoff Cement $281 \mathrm{~m}^{2} / \mathrm{kg}$ (Germany)

Dyckerhoff Cement $248 \mathrm{~m}^{2} / \mathrm{kg}$ (Germany)

Submit form for response

Return to Homepage for Partnership for High Performance Concrete Technology

Figure 2: Form to select a cement from the cement images database. 


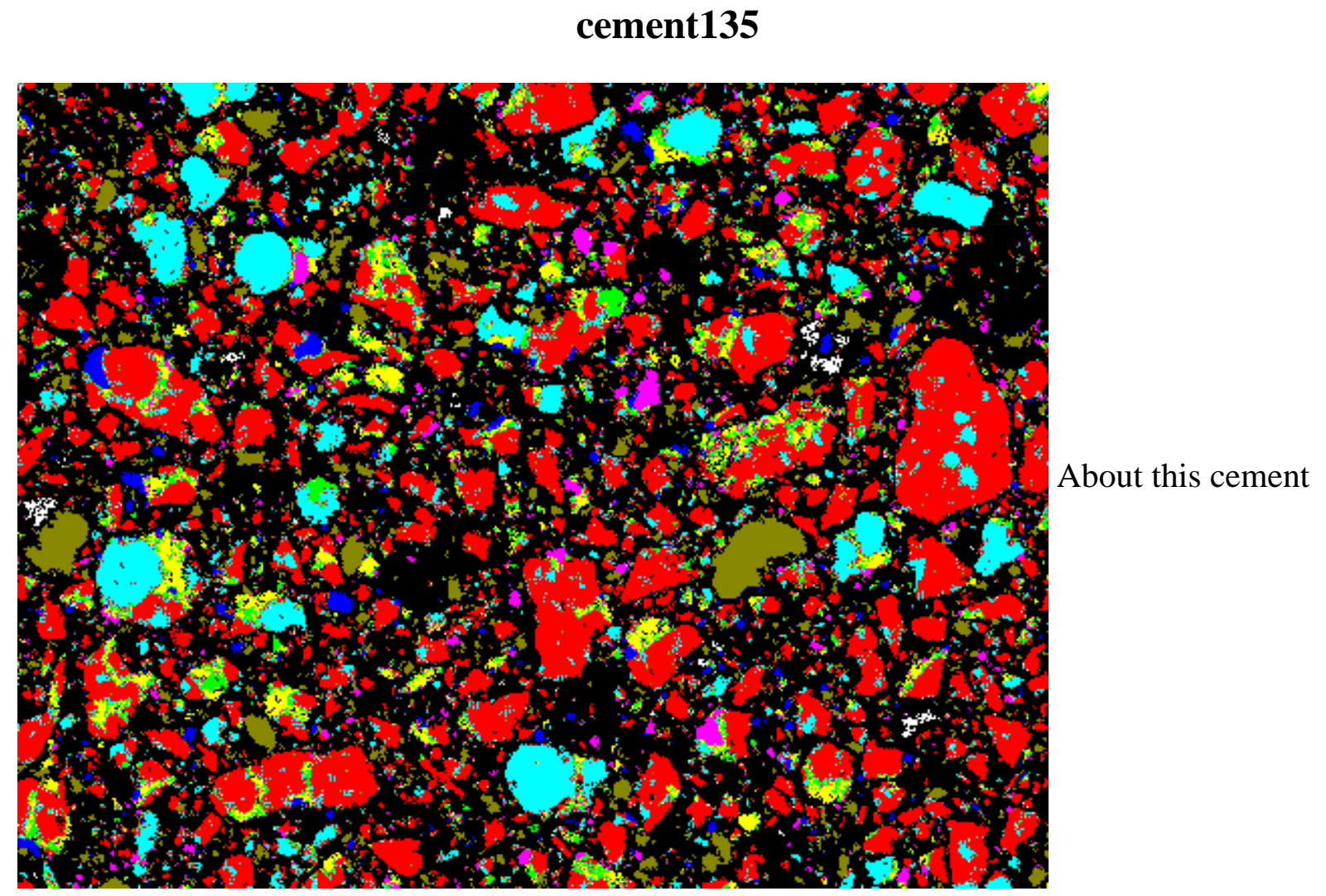

Figure 3: First half of page from cements image database for Cement 135. 
Discretized Cement Particle Size Distribution

\begin{tabular}{||l|l|l|l||}
\hline Diameter_(um) & Wt._frac. & Part_vol & Number_frac \\
\hline 1.0 & 0.177775 & 1 & 0.956205 \\
\hline 3.0 & 0.121252 & 19 & 0.034325 \\
\hline 5.0 & 0.087078 & 81 & 0.005782 \\
\hline 7.0 & 0.067035 & 179 & 0.002014 \\
\hline 9.0 & 0.055533 & 389 & 0.000768 \\
\hline 11.0 & 0.047494 & 739 & 0.000346 \\
\hline 13.0 & 0.042191 & 1189 & 0.000191 \\
\hline 15.0 & 0.038665 & 1791 & 0.000116 \\
\hline 17.0 & 0.036427 & 2553 & 0.000077 \\
\hline 19.0 & 0.032629 & 3695 & 0.000047 \\
\hline 21.0 & 0.031640 & 4945 & 0.000034 \\
\hline 23.0 & 0.028675 & 6403 & 0.000024 \\
\hline 25.0 & 0.027466 & 8217 & 0.000018 \\
\hline 27.0 & 0.023840 & 10395 & 0.000012 \\
\hline 29.0 & 0.023840 & 12893 & 0.000010 \\
\hline 31.0 & 0.028647 & 15515 & 0.000010 \\
\hline 35.0 & 0.041058 & 22575 & 0.000010 \\
\hline 41.0 & 0.035907 & 36137 & 0.000005 \\
\hline 47.0 & 0.031764 & 54435 & 0.000003 \\
\hline 61.0 & 0.016722 & 119009 & 0.000001 \\
\hline 73.0 & 0.004360 & 203965 & 0.000000 \\
\hline \hline
\end{tabular}

Access ftp site for these files

Figure 4: Second half of page from cements image database for Cement 135. 


\subsection{Menu Selection 2) Create a particle size distribution file}

This menu selection is used to create and store a PSD file which specifies the number of cement particles of each diameter to be placed in a starting 3-D microstructure. The output file created by this selection can be specified as input to Menu Selection 3) Generate an initial 3-D microstructure.

The form (shown in Figure 5) to create a PSD file consists of a table listing the diameter, mass fraction, and number of particles, followed by two entries to specify the total number of particles or the water-tocement ratio (w/c), respectively. The user may edit the mass fractions to match those obtained from one of the cements in the cements image database as discussed above. Then, they may either fix the number of particles and have the embedded JavaScript routine calculate the w/c, or fix the w/c with the number of particles being calculated. In addition, they may change any of the specific entries for the number of particles in the last column of the table. For example, the number of particles for all diameters larger than $41 \mu \mathrm{m}$ could be manually set to zero. For the automatic calculation of the number of particles when a w/c is specified, it may not always be possible to match exactly the desired w/c ratio, as one too many large particles may result in a substantial change in the w/c. In this case, the user may manually set the mass fraction of these larger diameter particles to zero and repeat the automatic calculation by respecifying the desired w/c value. As a final entry, the user supplies the name of the file to be created (with an extension of .psd being automatically added by the VCCTL program). 


\section{Inputs for Program Creatpsd}

Below this table, enter the total number of particles or the desired w/c ratio. You can also change the mass fractions or specifically fix the number(s) of certain size particles.

\begin{tabular}{|c|c|c|}
\hline Diameter $(\boldsymbol{\mu m})$ & Mass Fraction & Number of particles \\
\hline 1 & 0.1348 & 58217 \\
\hline 3 & 0.1303 & 2962 \\
\hline 5 & 0.09456 & 504 \\
\hline 7 & 0.07349 & 177 \\
\hline 9 & 0.06085 & 68 \\
\hline 11 & 0.0507 & 30 \\
\hline 13 & 0.04221 & 15 \\
\hline 15 & 0.03775 & 9 \\
\hline 17 & 0.033935 & 6 \\
\hline 19 & 0.028 & 3 \\
\hline 21 & 0.02565 & 2 \\
\hline 23 & 0.0233 & 2 \\
\hline 25 & 0.02115 & 1 \\
\hline 27 & 0.019 & 1 \\
\hline 29 & 0.019 & 1 \\
\hline 31 & 0.0228 & 1 \\
\hline 35 & 0.0347 & 1 \\
\hline 41 & 0.02658 & 0 \\
\hline 47 & 0.0454 & 0 \\
\hline 61 & 0.0358 & 0 \\
\hline 73 & 0.040025 & 0 \\
\hline
\end{tabular}

Total number of particles: $62000 \mathrm{w} / \mathrm{c}$ ratio is:

.49234

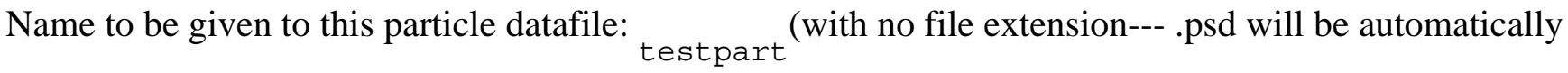
added)

User comment:

Submit form to store created PSD

\section{Return to the main menu}

Figure 5: Form to specify and store a PSD. 


\subsection{Menu Selection 3) Generate an initial 3-D microstructure}

Menu Selection 3 is used to create an initial 3-D microstructure consisting of cement (gypsum, and filler) particles in water. For this form, the user will find several entries that are highlighted (in blue). Clicking on any of these will direct the user to supplementary help information screens. Often, the articles referenced in these help screens are directly accessible online as part of the Electronic Monograph: Modelling and Measuring the Structure and Properties of Cement-Based Materials (available at http://ciks.cbt.nist.gov/monograph) [8].

The form for Menu Selection 3 is shown in Figures 6 through 8. The user must provide a negative integer random number seed (in the range [-1,-32767]), the thickness of the single aggregate particle (slab) placed in the middle of the 3-D microstructure (if any), and to what degree (if any) the particles are to be dispersed or flocculated. In addition, they must supply information on the calcium sulfate (gypsum) content and form (dihydrate, hemihydrate, and anhydrite). Here, the user specifies first the total volume fraction of randomly distributed calcium sulfate and then the fractions of this total that are to be assigned as hemihydrate and anhydrite, respectively (with the remainder being distributed as the dihydrate form of calcium sulfate). The specific PSD to be used in creating the 3-D microstructure must next be specified. For the PSD, the user has the choice of directly specifying the number and phase of each size particle via the table in Figure 7, or reading in this information from a PSD datafile created using Menu Selection 2, as discussed above. Finally, the user needs to specify a filename in which to store the created microstructure and their e-mail address. Once the execution of the genpartnew program is complete, an e-mail notification will be sent to the user at the specified e-mail address. If the genpartnew program is unable to place the requested numbers of particles, the user will be notified of this by e-mail as well, and instructed to modify their inputs and resubmit the form.

Calcium sulfate (gypsum) additions can be handled in one of two ways during the microstructure creation step. If only the composite PSD of the cement and gypsum is known, a specific fraction of the cement particles can be randomly assigned to be gypsum. Conversely, if both the PSDs of the cement and gypsum are available separately, the PSD table can be used to provide the specific numbers of each size particle which are to be cement and gypsum, respectively. In this case, the "Total randomly distributed calcium sulfate fraction" in Figure 6 would be specified to be 0.0. The same specifications can be done with cement and fly ash particles, or cement and inert filler particles. While the user can change the individual particle diameter entries in the table shown in Figure 7, they should be sure that the entries are always in descending order, starting with the largest diameter particles. This is to ensure that during random particle placement, there is the best chance that there is some open space available for the last (smallest) particles to be placed. If the smallest particles are randomly located first, there may not remain any empty spaces of adequate size to fit the (last) larger ones.

In addition, it should be noted that only particles 3 pixels $(\mu \mathrm{m})$ in diameter and larger are normally added during the execution of Menu Selection 3. The smaller 1-pixel diameter particles of the various cement clinker phases, gypsum, silica fume, etc. should instead be specified just prior to the hydration using a fill-in table with Menu Selection 13 (see Figure 15). This is done to allow the optional flocculation of the 3 pixel diameter and larger particles during the creation of the 3-D particle microstructure image. Because the 1pixel particles are generally quite large in number, their inclusion in the flocculation algorithm would result in dramatic increases in the memory and time requirements of the 3-D microstructure creation program. 


\section{Inputs for Program Genpartnew}

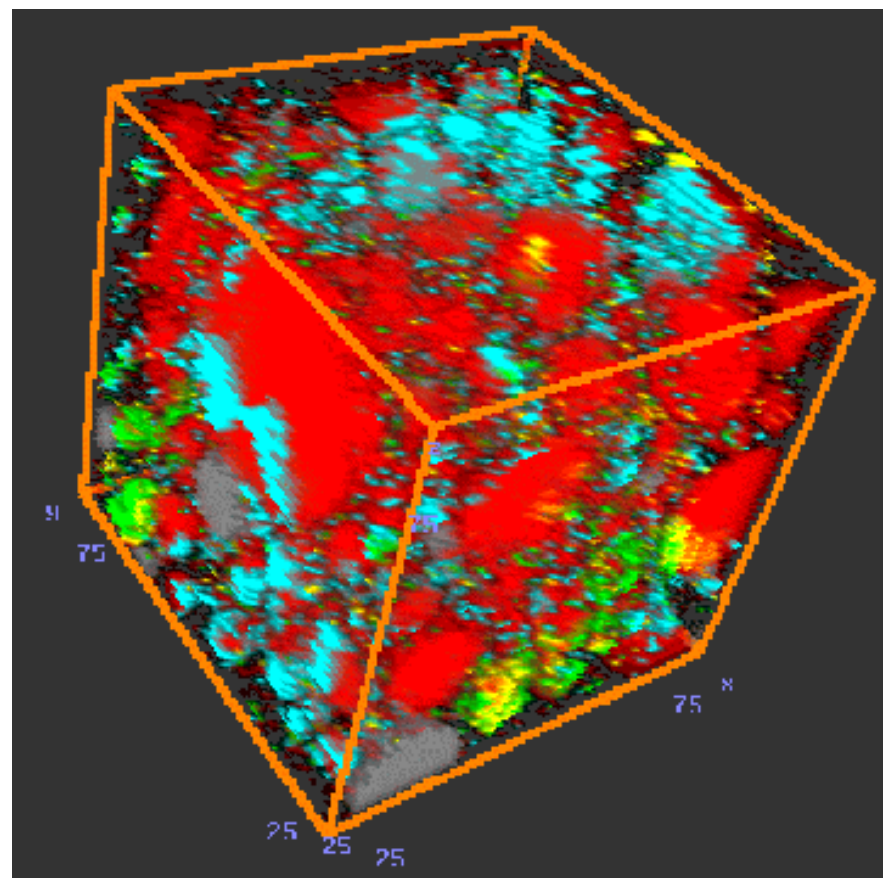

If an entry is highlighted in blue, you may click on it to receive help and reference information!

Random number seed (negative integer):

$$
-3034
$$

Aggregate present (default is off) Flocculation (default is none)

Aggregate thickness (pixels): 2 Number of flocs:

Dispersion distance between particles during placement:

\section{Sulfate additions:}

Total randomly distributed calcium sulfate fraction is 0.05 with:

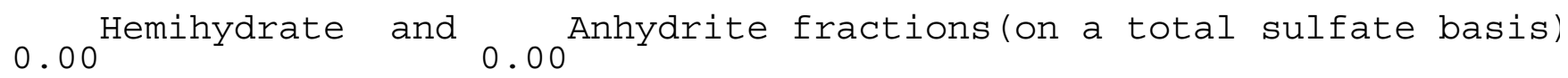

\section{Particle Size Distribution:}


Input PSD in table provided below

Read PSD from datafile (include extension in name):

part001.psd

\section{Click on boxes under Phase to select}

(defaults for cement will give a w/c of about 0.4 )

\begin{tabular}{|c|c|c|}
\hline Diameter $(\mu \mathrm{m})$ & Number of Particles & Phase \\
\hline 41 & 0 & cement $(\mathrm{C} 3 \mathrm{~S})$ \\
\hline 41 & 0 & fly ash \\
\hline 37 & 0 & cement(C3S) \\
\hline 37 & 0 & fly ash \\
\hline 35 & 1 & cement(C3S) \\
\hline 35 & 0 & fly ash \\
\hline 33 & 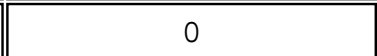 & cement $(\mathrm{C} 3 \mathrm{~S})$ \\
\hline 33 & 0 & fly ash \\
\hline 31 & 1 & cement $(\mathrm{C} 3 \mathrm{~S})$ \\
\hline 31 & 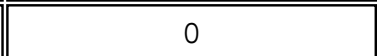 & fly ash \\
\hline 29 & 1 & cement $(\mathrm{C} 3 \mathrm{~S})$ \\
\hline 29 & 0 & fly ash \\
\hline 27 & 1 & cement $(\mathrm{C} 3 \mathrm{~S})$ \\
\hline 27 & 0 & fly ash \\
\hline 25 & 1 & cement $(\mathrm{C} 3 \mathrm{~S})$ \\
\hline 25 & 0 & fly ash \\
\hline 23 & 2 & cement $(\mathrm{C} 3 \mathrm{~S})$ \\
\hline 23 & 0 & fly ash \\
\hline 21 & 3 & cement $(\mathrm{C} 3 \mathrm{~S})$ \\
\hline 21 & 0 & fly ash \\
\hline 19 & 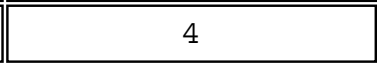 & cement $(\mathrm{C} 3 \mathrm{~S})$ \\
\hline 19 & 0 & fly ash \\
\hline 17 & 7 & cement $(\mathrm{C} 3 \mathrm{~S})$ \\
\hline 17 & 0 & fly ash \\
\hline 15 & 10 & cement $(\mathrm{C} 3 \mathrm{~S})$ \\
\hline 15 & 0 & fly ash \\
\hline 13 & 18 & cement $(\mathrm{C} 3 \mathrm{~S})$ \\
\hline 13 & 0 & fly ash \\
\hline
\end{tabular}

Figure 7: Form to create a starting 3-D particle microstructure (continued). 


\begin{tabular}{||c||c|c||}
\hline 11 & 34 & cement(C3S) \\
\hline \hline 11 & 0 & fly ash \\
\hline \hline 9 & 77 & cement(C3S) \\
\hline \hline 9 & 0 & fly ash \\
\hline \hline 7 & 203 & cement(C3S) \\
\hline \hline 7 & 0 & fly ash \\
\hline \hline 5 & 578 & cement(C3S) \\
\hline \hline 5 & 0 & fly ash \\
\hline \hline 3 & 6903 & cement(C3S) \\
\hline 3 & 0 & fly ash \\
\hline
\end{tabular}

Name to be given to this microstructure: ${ }_{\text {newcem }}$ (do not add a file extension as .img will be automatically added)

E-mail address:

\section{Please be patient, may take 3-5 minutes to execute, once you press submit.}

\section{You will be e-mailed at the above address when execution is complete.}

Submit form to execute genpartnew

\section{Return to the main menu}

Figure 8: Form to create a starting 3-D particle microstructure (continued). 


\subsection{Menu Selection 4) View a 2-D slice from any 3-D microstructure}

Menu Selection 4 is used to create and view a 2-D slice from any existing 3-D microstructure (starting, hydrated, leached, etc.). The user simply supplies the name of the image to be displayed, the z-plane (slice) to be used in generating the 2-D x-y slice from the 3-D microstructure, and a magnification factor (1X to 10X) for viewing the 2-D slice. The VCCTL will locate the proper slice of the selected image and display a 2-D color image of the microstructure, along with a key identifying the phases corresponding to each color. Example images are provided later in this manual, in Figures 23 to 26. If this selection is used repeatedly with the same 3-D image filename, depending on the user's Internet browser settings and preferences, they may need to use the Reload or Refresh button on their browser to refresh the displayed image to be the currently selected one. In the extreme cases where this button doesn't load the newly generated image, the user will need to restart their Internet browser or use some other measure to force it to empty the previous image from its cache.

\subsection{Menu Selection 5) Generate an animation from any 3-D microstructure}

An alternate method of viewing a microstructure is provided by Menu Selection 5. This selection can be used to create an animated gif ("fly through") file for a user-specified 3-D microstructure. For this selection, the user supplies the following information before submitting the displayed form:

1) the name of the microstructure to be animated,

2) a new filename in which to store the animated gif file,

3) the number of 2-D slices to include in the animation $(0,100)$, and

4) the magnification (1X-10X) to use for the animation images.

The first slice of the microstructure is always used as the starting slice for the 3-D animation generation. Typically, to generate a complete (100 slice) animation of a 3-D microstructure will require 15 min to $20 \mathrm{~min}$ of CPU time. Thus, the user should wait for this period of time before trying to view the animation using Menu Selection 6. The VCCTL is set up to create only one animation at any specific time. Therefore, if the system is busy creating one animation when another request is submitted, the user will be notified to resubmit their job at a later time.

\subsection{Menu Selection 6) View an animation from any 3-D microstructure}

Menu Selection 6 is simply used to view the animated gif files created using Menu Selection 5. The user need only supply the name of the animated gif file to be displayed. The animated gif file will be displayed five times from start to finish, showing each slice processed in creating the animation.

\subsection{Menu Selection 7) Distribute all phases amongst cement particles}

Once an initial arrangement of cement (and gypsum, fly ash, etc.) particles in water has been created, Menu Selection 7 may be used to distribute the four major cement clinker phases amongst the cement particles. To do this, the 3-D microstructure image is filtered using the correlation files measured on the actual 2-D SEM images of the cement of interest $[1,2,6]$. The filtering process and subsequent thresholding and "sintering" are conducted in such a way as to match the volume and surface area fractions previously determined for each of the four major cement clinker phases, and provided as input via the table shown in the form in Figure 9. For example, these 3-D phase volume and surface area fractions might be obtained from the 2-D area and perimeter fractions given in the corresponding About this cement page in the cement images database (Menu Selection 1). The user could simply print this page and type the appropriate values into the table for volume and surface area fractions. 
To use Menu Selection 7, the user must specify a negative integer to be used as a random number seed and the names of the original and final (processed) microstructures, and select the correlation files (from a pulldown menu) to be used in filtering the original microstructure. In addition, they must fill in the table providing the volume and surface area fractions of each of the four major cement clinker phases and provide their e-mail address in order to receive a notification when the processing is complete. Ordinarily, on the order of 20 min of CPU time is required to distribute the various phases amongst the original cement particles. The VCCTL is set up to perform only one phase distribution at any specific time. Therefore, if the system is busy distributing phases for one microstructure when another request is submitted, the user will be notified to resubmit their job at a later time. 


\section{Inputs for Program Distrib3d}
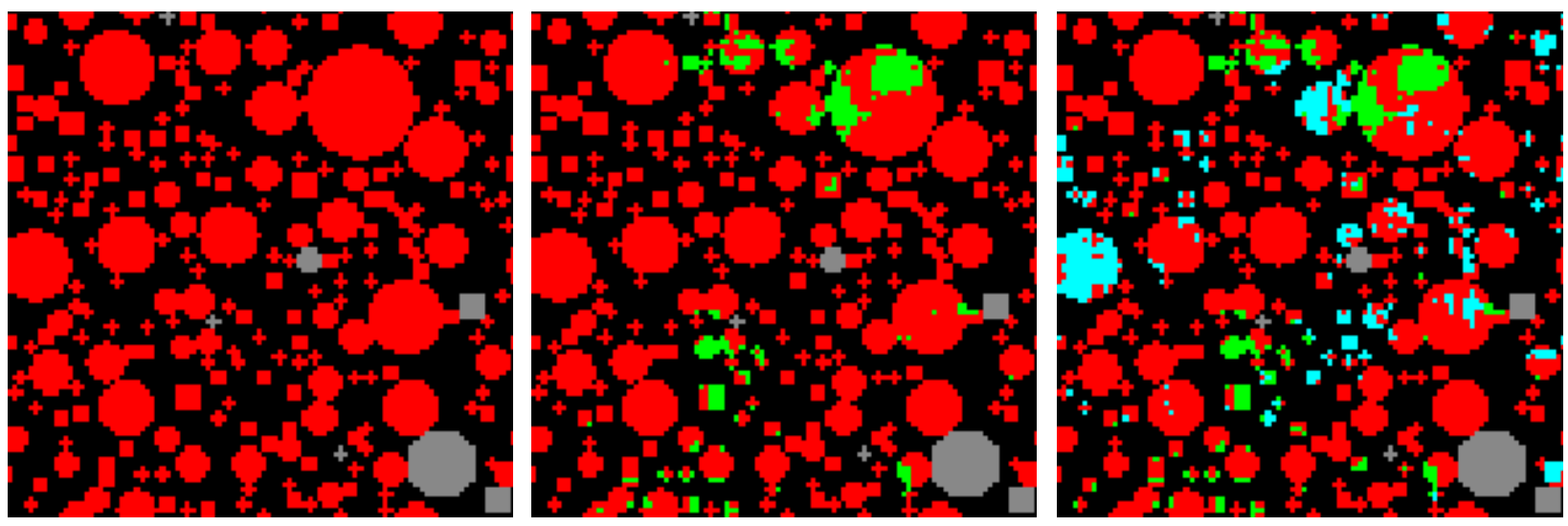

Access the latest version of the hydration manual to read about phase distribution

Random number seed (negative integer): $-3034$

Filename of original microstructure: cem133wc030n1. img

Filename of the final microstructure: cem133wc030n1f.img

Processed cement to use for the correlation files: cem133r

Phase volume (area) and surface fractions for the cement being generated:

$\begin{array}{ccc}\text { Phase } & \text { Volume fraction } & \begin{array}{c}\text { Surface area } \\ \text { fraction }\end{array} \\ \mathrm{C}_{3} \mathrm{~S} & 0.7018 & 0.6491 \\ \mathrm{C}_{2} \mathrm{~S} & 0.1315 & 0.1764 \\ \mathrm{C}_{3} \mathrm{~A} & 0.0827 & 0.1138 \\ \mathrm{C}_{4} \mathrm{AF} & 0.0840 & 0.0607\end{array}$

E-mail address:

You will be e-mailed at the above address when execution is complete. Submit form to execute distrib3d

\section{Return to the main menu}

Figure 9: Form to specify inputs to be used in distributing phases amongst cement particles. 


\subsection{Menu Selection 8) Filter a 3-D microstructure to distribute only two phases amongst cement particles}

Normally, the user will apply Menu Selection 7 to automatically distribute all four phases amongst the initial cement particles. However, in those cases where special control over the distribution process is needed, the user may control each step in the distribution process using Menu Selections 8, 9, and 10. Specifically, Menu Selection 8 is used to filter a 3-D image using a specific correlation file for a specific cement. Basically, an image of random noise is superposed on the random particle microstructure image and filtered by (convolved with) the correlation function for one or more phases determined from the 2-D SEM images. Then, the correlated noise image is thresholded to separate one phase of the microstructure into two phases, with the user specifying the desired volume fraction of each phase. For example, initially, the cement particles are separated into silicates and aluminates using a cemXXX.sil correlation file [1]. In subsequent passes of this algorithm, the silicates are separated into $C_{3} S$ and $C_{2} S$, while the aluminates are separated into $C_{3} A$ and $C_{4} A F$. When the user executes Menu Selection 7, all three passes are conducted in one execution of the program.

To execute the filtering (rand3d) program, the user must supply a random number seed, the names of the input and output microstructures, the correlation file to be used, the volumetric phase fraction of the first phase to be retained after the filtering, and their e-mail address. As with many of the other menu selections, the user will be notified by an e-mail message once execution of the filtering is complete. The VCCTL is set up to perform only one microstructure filtering at any specific time. Therefore, if the system is busy filtering one microstructure when another request is submitted, the user will be notified to resubmit their job at a later time. 


\section{Inputs for Program Rand3d}
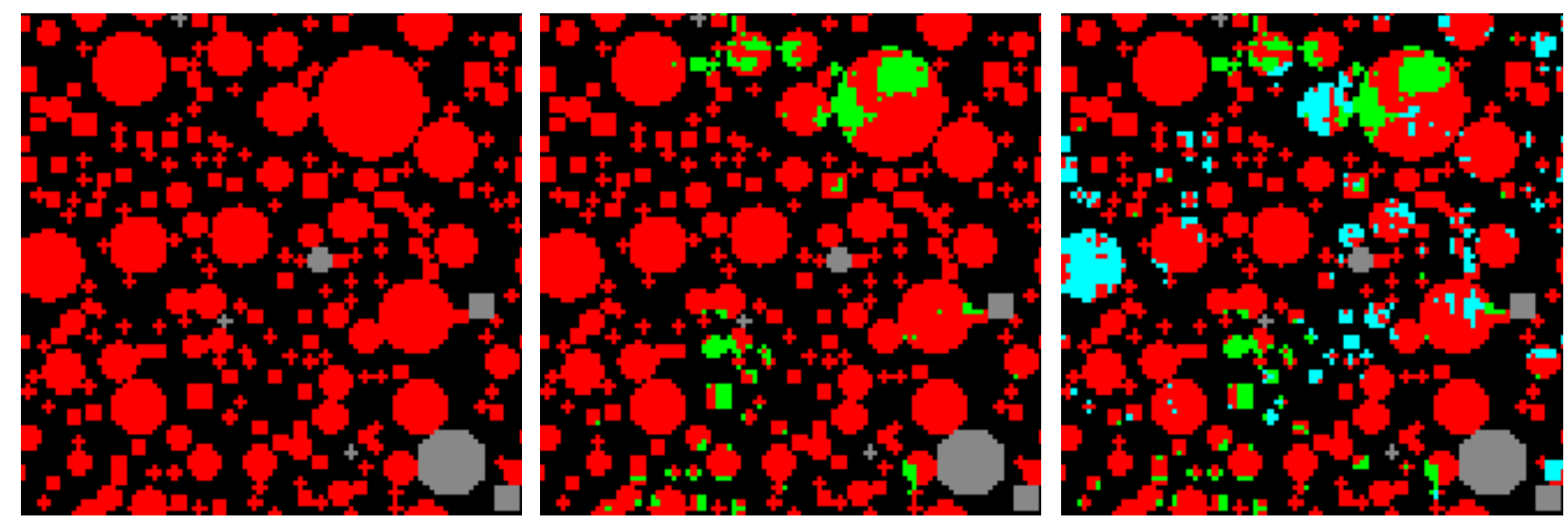

Access the latest version of the hydration manual to read about image filtering

Random number seed (negative integer): $-3034$

Filename of original microstructure: newcem. img

Filename of the new microstructure: newcemla.img

Filename of the correlation file: cem133r.sil

Fraction of first phase to be maintained as is: 0.50

E-mail address:

You will be e-mailed at the above address when execution is complete.

Submit form to execute rand $3 \mathrm{~d}$

\section{Return to the main menu}

Figure 10: Form to specify inputs to be used in filtering a 3-D microstructure. 


\subsection{Menu Selection 9) Compute spatial statistics for a 3-D microstructure}

Menu Selection 9 can be used to measure the volume and surface pixel counts for each phase present in any 3-D microstructure. This menu selection can be employed during the creation of an initial microstructure, after hydration of an initial microstructure, or after leaching of a hydrated microstructure. To use this selection, the user need only supply the name of the 3-D microstructure image file to be analyzed. Within one minute to two minutes from submitting the form, a table of the volume and surface counts, such as that shown in Figure 11, will be returned to the user. In this case, the volume and surface fractions for the four major clinker phases in an analyzed image can be compared to those requested using Menu Selection 7 (see Figure 9), with a very good agreement being observed. 


\section{Resultant statistics for cem133wc030n1f.img}

\begin{tabular}{|c|c|c|c|c|c|}
\hline$\overline{\text { Phase }}$ & $\begin{array}{l}\text { Phase } \\
\text { ID }\end{array}$ & $\begin{array}{l}\text { Volume } \\
\text { count }\end{array}$ & $\begin{array}{l}\text { Surface } \\
\text { count }\end{array}$ & $\begin{array}{l}\text { Volume } \\
\text { fraction }\end{array}$ & $\begin{array}{l}\text { Surface } \\
\text { fraction }\end{array}$ \\
\hline Porosity & 0 & 569660 & 0 & & \\
\hline C3S & 1 & 284464 & 293128 & 0.69948 & 0.64804 \\
\hline $\mathrm{C} 2 \mathrm{~S}$ & 2 & 53645 & 80013 & 0.13191 & 0.17689 \\
\hline C3A & 3 & 33982 & 51716 & 0.08356 & 0.11433 \\
\hline $\mathrm{C} 4 \mathrm{AF}$ & 4 & 34591 & 27471 & 0.08506 & 0.06073 \\
\hline Total & & 406682 & 452328 & & \\
\hline Gypsum & 5 & 23658 & 23382 & & \\
\hline Hemihyd. & 6 & 0 & 0 & & \\
\hline Anhydrite & 7 & 0 & 0 & & \\
\hline Pozzolan & 8 & 0 & 0 & & \\
\hline Inert & 9 & 0 & 0 & & \\
\hline ASG & 10 & 0 & 0 & & \\
\hline CAS2 & 11 & 0 & 0 & & \\
\hline $\mathrm{CH}$ & 12 & 0 & 0 & & \\
\hline $\mathrm{C}-\mathrm{S}-\mathrm{H}$ & 13 & 0 & 0 & & \\
\hline С3АН6 & 14 & 0 & 0 & & \\
\hline Ettringite & 15 & 0 & 0 & & \\
\hline Ettringite & 16 & 0 & 0 & & \\
\hline Afm & 17 & 0 & 0 & & \\
\hline FH3 & 18 & 0 & 0 & & \\
\hline PozzC-S $-\mathrm{H}$ & 19 & 0 & 0 & & \\
\hline $\mathrm{CaCl} 2$ & 20 & 0 & 0 & & \\
\hline Freidelsalt & 21 & 0 & 0 & & \\
\hline Stratlingite & 22 & 0 & 0 & & \\
\hline Sec. gypsum & 23 & 0 & 0 & & \\
\hline Inertagg & 24 & 0 & 0 & & \\
\hline Abs. gypsum & 25 & 0 & 0 & & \\
\hline Fly ash & 26 & 0 & 0 & & \\
\hline C3A (fly ash) & 35 & 0 & 0 & & \\
\hline
\end{tabular}

Return to the main menu

Figure 11: Results from spatial statistics analysis of an initial 3-D microstructure. 


\subsection{Menu Selection 10) Sinter a 3-D microstructure to adjust the hydraulic radius of one phase}

Following the filtering process (Menu Selection 8), the surface area fractions of the filtered phases (from Menu Selection 9) may not match those of the phases in the starting 2-D SEM images. These surface area fractions can be adjusted using a 3-D "sintering" algorithm to swap specific locations of the two phases in a manner that obtains the desired surface area fractions. Details of the 3-D sintering algorithm have been published previously [9], with the specific application to cement particles described in the CEMHYD3D Version 2.0 user's manual [1].

The input form for Menu Selection 10 is shown in Figure 12. The user must supply a negative integer random number seed, the names of the input and output images, the desired (target) hydraulic radius of the phase being sintered, and the phase IDs of the two phases between which to execute the sintering algorithm. The target hydraulic radius of a phase can be calculated (based on the volume count provided with Menu Selection 9) as [1]:

$$
R_{h}=\frac{6}{4} \times \frac{\text { volume of phase in pixels }}{\text { desired surface area count in pixels }} .
$$

The factor of 6 over 4 is included to correct for the difference between the approximate surface area of a digitized (pixel-based) sphere and a continuum one of the same diameter. It should be noted that the hydraulic radius of a phase can only be increased when applying the sintering algorithm to it. If it is necessary to decrease the hydraulic radius of a phase, the algorithm should be executed so as to increase the hydraulic radius of the secondary phase, thus decreasing that of the primary one [1]. 


\section{Sinter a 3-D microstructure to adjust hydraulic radius}

Please refer to the cement hydration manual for more details.

Random number seed: $-24$

Image file name to be sintered(complete with extension):

Desired hydraulic radius for first phase:

$$
1.50
$$

Phases to execute sintering between: ${ }_{1}$ and ${ }_{4}$

New image file name to create(complete with extension):

output.img

Please be patient, may take 3-5 minutes to sinter the image after you submit.

Submit form to sinter microstructure

Return to the main menu

Figure 12: Form to specify inputs to be used in "sintering" a 3-D microstructure. 


\subsection{Menu Selection 11) Distribute fly ash phases amongst fly ash particles}

While Menu Selections 8 to 10 could possibly be used to distribute phases amongst fly ash particles as well as cement particles, Menu Selection 11 has been developed specifically for the distribution of phases amongst fly ash particles, under two simplifying cases. In the first case, the particles are assumed to be monophase and the particles are randomly assigned phases to achieve the desired phase volume fractions. In the second, the phases are simply randomly distributed amongst all of the pixels identified as fly ash in the 3-D particle microstructure. This would imply a very fine and relatively uniform distribution of the fly ash phases amongst the individual particles. Currently, the following phases are considered for distribution amongst the fly ash particles: aluminosilicate, calcium aluminodisilicate, silica, anhydrite, calcium chloride, tricalcium aluminate, and an inert phase. Reactions between these phases and the main components of cement have been incorporated into the current version of the cement hydration model $[1,10]$.

To execute Menu Selection 11, the user provides a negative integer random number seed, selects whether distribution is to be done on a random particle or a random pixel basis, and fills in the remainder of the form shown in Figure 13. The user must provide the original microstructure and particle microstructure filenames, the name of an output file to hold the processed microstructure, the number of fly ash pixels in the 3-D microstructure (can be determined using Menu Selection 9 above), the desired volume fractions for the various fly ash phases, and their e-mail address. The particle microstructure image is needed for the case where the phases are distributed randomly amongst the particles, one phase per particle. When fly ash particles are placed during the creation of a microstructure (Menu Selection 3), they are assigned a phase ID of 26. Thus, when using Menu Selection 9, the user must be sure to note the volume count for phase ID 26 and use it as the correct value for the fly ash count in the form shown in Figure 13. 


\title{
Inputs for Distributing Phases within Fly Ash
}

Random number seed (negative integer): -3217

Distribute fly phases randomly on a particle basis

Distribute fly phases randomly on a pixel basis

Name of input phase microstructure file (with extension):

newcem.img

Name of input particle microstructure file (with extension):

pnewcem.img

(typically this is the phase microstructure file with a $\mathrm{p}$ in front of it)

Name of output phase microstructure file to create (with extension): newceml.img

Number of fly ash pixels (from executing stat3d-phase 26 is fly ash): 10000

\section{Phase fractions (remainder will be considered as inert):}

\author{
Phase \\ Aluminosilicate glass: \\ Volume (number) fraction \\ 0.10
}

Calcium alumina disilicate:

0.25

Tricalcium aluminate:

0.00

Calcium chloride:

Silica:

0.00

Silica: 0.40

Anhydrite $\left(\mathrm{CaSO}_{4}\right)$ :

0.05

E-mail address:

dale.bentz@nist.gov

\section{Return to the main menu}

Submit form to execute distribution of fly ash phases

Figure 13: Form to specify inputs to be used in distributing the phases amongst the fly ash particles. 


\subsection{Menu Selection 12) Input a temperature history (curing) file}

The CEMHYD3D cement hydration model can be executed under a variety of curing conditions (isothermal, adiabatic, or user-programmed temperature history). Menu Selection 12 is used to specify a controlled temperature history to be used in the hydration process (Menu Selection 13). The user simply fills in a table of starting and ending times with the corresponding temperatures. A linear change in temperature with time is assumed between the starting and ending points. Currently, the table is limited to six separate entries which should be adequate to specify a steam curing profile, for example. In addition to the values for the table, the user also specifies a filename in which to store the temperature history so that it may be accessed later during the execution of the hydration module.

\section{Inputs for Program Tempstore}

Filename to be created:

tempnew.dat

\section{Temperature History for Curing:}

Note that the starting and ending times should define a piecewise continuous curve (e.g., starting time (I+1) should equal ending time (I)).

Starting time

(h)

0.0

4.0

5.0

29.0

40.0

1000.0

\section{Ending time (h)}

4.0

5.0

29.0

40.0

1000.0

40000.0
Starting temperature $(C)$

25.0

25.0

60.0

60.0

25.0

25.0
Ending temperature

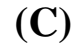

25.0

60.0

60.0

25.0

25.0

25.0

\section{Submit form to store temperature history}

\section{Return to the main menu}

Figure 14: Form to specify the temperature history to be used in curing a microstructure during hydration. 


\subsection{Menu Selection 13) Hydrate a 3-D microstructure}

The core of the VCCTL is Menu Selection 13 as it permits one to read in a starting microstructure, add some one-pixel particles (if needed), and perform hydration under user-specified curing conditions. The fill-in forms for doing this are shown in Figures 15 through 17. As with several other selections from the main menu, the VCCTL is currently set up to perform only one hydration at any specific time. Therefore, if the system is busy executing a hydration when another request is submitted, the user will be notified to resubmit their job at a later time.

To begin with, the user supplies a negative integer random number seed, and the names of the starting cement microstructure and particle image (typically the original image filename with the letter $p$ in front of it) files to be used in the hydration. Then, they have the option of adding some one-pixel particles of various phases prior to the execution of the hydration. This table should be used to add the one-pixel (1 $\mu$ m diameter) particles necessary to complete the cement PSD [1]. The exact number of one-pixel particles for each of the four cement phases and gypsum (or hemihydrate or anhydrite) can be determined from the volume counts (Menu Selection 9) for the final created 3-D microstructure along with the PSD established via Menu Selection 2, for example. Menu selection 2 will provide the total number of one-pixel particles to add, while Menu Selection 9 (along with the known phase compositon of the cement) will allow calculation of how this total number of one-pixel particles should be distributed to create a 3-D system that matches the desired overall phase composition of the cement [1]. A simple JavaScript routine to aid in this calculation is available as a help screen by clicking on the highlighted Number of one pixel particles to add:. Additionally, one-pixel particles of silica fume, an inert filler, or one phase of the user's choice can be added via this table.

The user then specifies the parameters that will control the hydration including:

1) the number of cycles of hydration to be executed,

2) the thermal curing conditions (isothermal, adiabatic, or temperature-defined),

3) the initial saturation curing conditions (saturated or sealed),

4) whether the conversion of primary $C-S-H$ to pozzolanic $C-S-H$ is prohibited or allowed (this selection is only relevant when pozzolanic materials such as silica fume or fly ash are present in the starting microstructure),

5) the frequencies in cycles to evaluate the water-filled porosity percolation, the percolation of total solids, and the individual particle hydration rates (these can be "disabled" by setting the frequencies to values larger than the requested number of cycles of hydration),

6) the initial curing temperature,

7) an estimate of the activation energy for cement hydration,

8) an estimate of the activation energy for the pozzolanic reactions,

9) the conversion factor to go from cycles of hydration to $h$ of real time, and

10) the aggregate volume fraction in a concrete mixture (used for prediction of the adiabatic heat signature of a concrete - can be set to 0.0 or left as is for cement paste systems).

Finally, the user once again supplies their e-mail address so that they may be notified when the hydration is completed. All of the parameters listed above are described in detail in Version 2.0 of the CEMHYD3D user's manual [1], and some of the entries in the form are highlighted in blue, indicating that supplemental help screens are directly available for viewing by clicking on the highlighted blue entry.

During the hydration, a number of output files are created by the CEMHYD3D program. These all utilize the starting microstructure filename as their root and add on appropriate extensions to indicate the 
results that each one contains. For example, if a file cemnew.img is hydrated for 4000 cycles of hydration at a starting temperature of $25^{\circ} \mathrm{C}$ and under isothermal and saturated conditions, the following output files will normally be created:

1) cemnew.img.4000.25.000 - microstructure image file after the hydration; the 4000 indicates the number of cycles of hydration, the 25 indicates the starting temperature, and the 000 indicates the selections for conversion of primary $C-S-H$ to pozzolanic $C-S-H$ (prohibited=0, allowed=1), thermal curing (isothermal $=0$, adiabatic $=1$, temperature-defined $=2$ ), and initial saturation (saturated $=0$, sealed $=1$,

2) cemnew.heat.4000.25.000 - output file containing a listing of the degree of hydration (both volume and mass bases), computed heat released, and computed gel-space ratio [11] vs. number of hydration cycles and computed real hydration time,

3) cemnew.adi.4000.25.000 - output file containing a listing of the system temperature vs. computed real hydration time,

4) cemnew.chs.4000.25.000 - output file containing a listing of the chemical shrinkage vs. number of hydration cycles and computed real hydration time,

5) cemnew.pha.4000.25.000 - output file containing a listing of the phase volume counts vs. number of hydration cycles,

6) cemnew.pps.4000.25.000 - output file containing a listing of the results for the examination of the percolation of the water-filled capillary porosity vs. cycles, computed hydration time, and degree of hydration,

7) cemnew.pts.4000.25.000 - output file containing a listing of the results for the examination of the percolation of the total solids vs. cycles, computed hydration time, and degree of hydration, and

8) cemnew.phr.4000.25.000 - output file containing a listing of the results for the hydration degree of individual particles after specific numbers of hydration cycles.

When Menu Selection 13 is executed, all of the user input parameters are echoed back in a form, along with the names of all of the output files that may be created by the CEMHYD3D program. However, normally, users don't need to concern themselves with the contents of these files, as they can instead use Menu Selection 17 to plot any specific property of interest for the systems that have been hydrated using Menu Selection 13. 


\section{Inputs for Program CEMHYD3D}

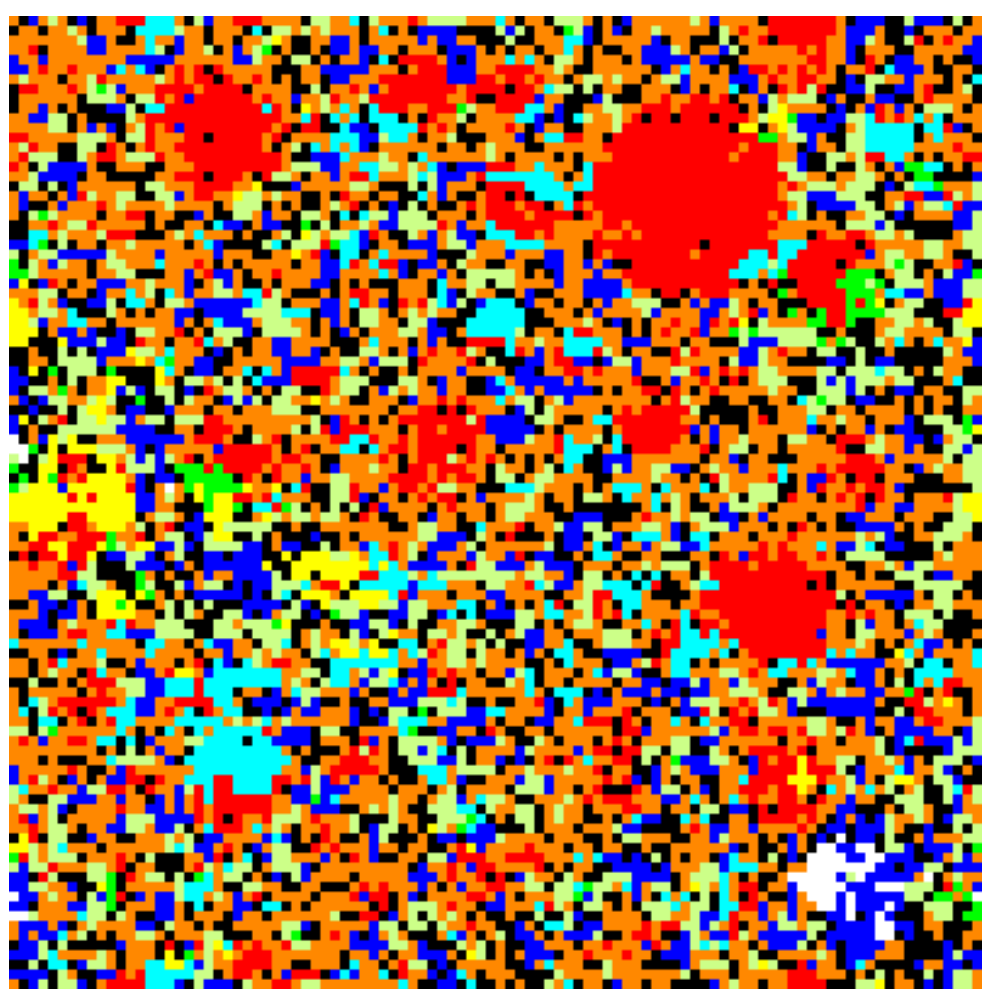

\section{Access the latest version of the hydration manual}

Random number seed (negative integer):

$$
-3999
$$

Filename of starting cement microstructure:

Filename of original particle microstructure:

Number of one pixel particles to add:
Phase
Number to add
$\mathrm{C}_{3} \mathrm{~S}$ :
45921
$\mathrm{C}_{2} \mathrm{~S}:$ 


$$
\mathrm{C}_{3} \mathrm{~A}:
$$

$\mathrm{C}_{4} \mathrm{AF}:$

Gypsum:

Hemihydrate:

Anhydrite:

Silica fume:

Inert filler:

Phase $0: 0$

Number of cycles of hydration to execute: ${ }_{100}$

Curing thermal conditions: isothermal Temperature history filename: tempone.dat

Curing saturation conditions: saturated

Conversion of primary $\mathrm{C}-\mathrm{S}-\mathrm{H}$ to pozzolanic $\mathrm{C}-\mathrm{S}-\mathrm{H}$ is: prohibited

Frequency (in cycles) to evaluate percolation of porosity: ${ }_{50}$

Frequency (in cycles) to evaluate percolation of total solids (set): ${ }_{5}$

Frequency (in cycles) to evaluate individual particle hydration: 5000

Initial temperature: ${ }_{25.0}{ }^{\circ} \mathrm{C}$ 
Activation energy for cement hydration: ${ }_{40.0} \mathrm{~kJ} / \mathrm{mole}$

Activation energy for pozzolanic reactions: ${ }_{83,14} \mathrm{~kJ} / \mathrm{mole}$

Conversion factor to go from cycles to time:

0.0003

Aggregate volume fraction in a concrete mixture:

0.72

E-mail address:

dale.bentz@nist.gov

Submit form to execute cemhyd3d

\section{Return to the main menu}

Figure 17: Form to hydrate a starting 3-D microstructure (continued). 


\subsection{Menu Selection 14) Measure phase fractions vs. distance from aggregate}

Menu Selection 14 can be used to analyze the phase fractions present as a function of distance from an aggregate surface, for microstructures that were originally created containing an aggregate particle. The user supplies the name of the microstructure to be analyzed, and a file with an .agg extension replacing the .img portion of the submitted filename is created containing the quantitative phase count results. In addition, if the user provides their e-mail address, this same file will be sent to them for further analysis and plotting, in their own spreadsheet package for example. For each incremental pixel distance away from the aggregate, the file lists the distance in pixels and the phase counts for phase IDs 0 (water-filled porosity) to 26 (fly ash) and phase IDs 35 ( $C_{3} A$ in fly ash before hydration is executed) and 38 (empty porosity). All of the phases and their corresponding IDs are provided in Figure 11.

\subsection{Menu Selection 15) Leach $\mathrm{CH} /$ cement from a hydrated microstructure}

Menu Selection 15 can be used to selectively leach (remove) a portion or the complete volume of a phase(s) from a hydrated microstructure. The calcium hydroxide $(\mathrm{CH})$ and the initial four cement clinker phases are all leachable, with the user selecting which phases to include in a specific execution of the leaching algorithm. As shown in the input form in Figure 18, the user must supply the filename of the microstructure to be leached, a new filename in which to store the microstructure after leaching, the phases to be leached, the number of leaching cycles to execute or to entirely leach the selected phases from the microstructure, a leaching probability ( $p_{l}$ in the range 0.0-1.0), a negative integer random number seed for the leaching process, and their e-mail address. The leaching probability can be used to control the amount of a phase(s) leached in a given cycle. If a given leachable phase pixel is in contact with pore space, it will be leached with probability $p_{l}$ (and remain as is with probability 1- $p$ ). In this way, microstructures with "leached" levels less than that removed during a single cycle of full $(p=1.0)$ leaching can be created for subsequent evaluation. 


\section{Leaching of phases from a 3-D microstructure}

Access a paper about the effects of leaching on pore space percolation and diffusivity.

Image file name to be leached (complete with extension):

File name for final leached image (complete with extension):

Phases to be leached (default is $\mathrm{CH}$ only):

$\mathrm{CH} \mathrm{C}_{3} \mathrm{~S} \mathrm{C}_{2} \mathrm{~S} \mathrm{C}_{3} \mathrm{~A} \mathrm{C}_{4} \mathrm{AF}$

Leaching execution:

Leach for 100 cycles

Leach selected phases completely from microstructure

1.0 leaching probability

-34 random number seed for leaching

E-mail address:

\section{It may take 15-20 minutes to leach the image after you submit.}

You will be notified by e-mail at the above address when leaching is complete.

Submit form to execute the leaching

\section{Return to the main menu}

Figure 18: Form to specify inputs for leaching $\mathrm{CH} /$ cement from a hydrated 3-D microstructure. 


\subsection{Menu Selection 16) Evaluate percolation properties of a hydrated/leached microstruc- ture}

Menu Selection 16 can be used to evaluate the percolation properties of a phase(s) in a hydrated/leached microstructure. To use this selection, the user supplies the filename of the microstructure to be evaluated and selects the phase(s) to be evaluated from a pull-down menu. In version 1.0 of the VCCTL, the percolation properties of the following phases can be evaluated: water-filled porosity, total porosity, $\mathrm{CH}, C-S-H$, pozzolanic $C-S-H$, total $C-S-H$, ettringite, or stratlingite. An example of the results for a percolation evaluation of the water-filled porosity in an initial microstructure (cem133wc030n1f.img) is provided in the Table shown in Figure 19. For each of the three principal directions (x, y, and z), the VCCTL returns the total number of pixels of the phase of interest, the fraction of these pixels which are part of percolated (through) pathways through the microstructure, and the fraction of the total pixels which are accessible from one face of the microstructure. For the example shown in Figure 19, since no hydration has yet occurred, the initial water-filled porosity between cement particles is highly percolated, with nearly all of the water-filled porosity pixels being part of a percolated pathway.

\section{Resultant percolation properties for Water-filled porosity in cem133wc030n1f.img}

$\begin{array}{cccc}\text { Direction } & \text { Total } & \begin{array}{c}\text { Percolated } \\ \text { fraction }\end{array} & \begin{array}{c}\text { Accessible } \\ \text { fraction }\end{array} \\ - & \text { count } & 0.9994 & 0.9995 \\ \text { X } & 569660 & 0.9994 & 0.9994 \\ \text { Y } & 569660 & 0.9994 & 0.9994 \\ \text { Z } & 569660 & \end{array}$

\section{Return to the main menu}

Figure 19: Results for percolation of capillary porosity in microstructure cem $133 \mathrm{wc} 030 \mathrm{n} 1 \mathrm{f} . \mathrm{img}$.

\subsection{Menu Selection 17) Plot predicted properties (vs. experimental data)}

Menu Selection 17 is used both to plot the different predicted properties and to enter experimental data for comparison against the predicted values. Upon making this selection, the user is presented with a form with two pull down menus to select either a specific system for which to list the available plots or for which to enter a set of experimental data, as shown in Figure 20. Upon submitting this first form, a second form containing a table of the various options available either for plotting or data entry is returned (see Figure 21 for an example of the table returned in the case of plotting).

With this table, in the case of plotting, the user can select to create all available plots for a given system, or simply to create a single plot of interest. In all cases, the user can elect to include the experimental data (when available) on the plot. Typically, the computer model data is plotted using blue squares connected by a blue line, while the experimental data is shown as discrete red diamond data points. The plot is typically labelled with the name of the datafile from which it was created.

In Version 1.0 of the VCCTL, the following plots are available (when the appropriate data has been created during a hydration run): 


\title{
Virtual Cement and Concrete Testing Laboratory
}

List data files for plotting:

aalborgwc $27 f$

List data files for data entry:

aalborgwc $27 f$

\author{
Building and Fire Research Laboratory \\ National Institute of Standards and Technology \\ Gaithersburg, MD 20899
}

Figure 20: Form for selecting files to plot or for which to enter experimental data.

1) adiabatic heat signature plot- plot of system temperature vs. computed hydration time (not very interesting for hydration under isothermal conditions),

2) chemical shrinkage- plot of chemical shrinkage (ml/g cement) vs. computed hydration time (h),

3) hydration- plot of degree of hydration (mass basis) vs. computed hydration time,

4) heat release- plot of cumulative heat release ( $\mathrm{kJ} / \mathrm{kg}$ cement) vs. computed hydration time,

5) compressive strength- plot of estimated compressive strength (MPa) vs. computed hydration time (the user must provide a pre-factor to be used in the calculation of compressive strength based on Power's gel-space ratio theory [11]),

6) capillary porosity percolation- fraction connected capillary porosity vs. either total porosity or computed hydration time, and

7) total solids percolation- fraction connected "total solids" vs. either computed hydration time or degree of hydration.

If the user elects to enter experimental data corresponding to a specific simulated system, they have the option of downloading the data into the VCCTL from a datafile located on their own computer or to enter the data manually. In the latter case, the VCCTL will provide a fill-in table with two columns corresponding to the values to be plotted on the $\mathrm{x}$ and $\mathrm{y}$ axes, respectively. For example, for the case of an adiabatic heat signature, the user would have to enter the time-temperature results into this table and then simply submit the form (using the "Copy data" button above the data entry table) to store this datafile for later access during plotting. Always, when experimental data has been entered, the user has the option of including it on or omitting it from the associated simulation results plot. 


\section{Virtual Cement and Concrete Testing Laboratory}

\section{Plot Selection Form}

\section{Case: cem136wc04852f}

\begin{tabular}{|c|c|c|c|c|c|c|}
\hline Create All Plots & & & & & & \\
\hline $\begin{array}{c}\text { Include data: } \\
\text { strength prefactor } \\
95 \\
\mathrm{MPa}\end{array}$ & $\begin{array}{l}\text { Plot } \\
\text { Type }\end{array}$ & $\begin{array}{l}\text { Number } \\
\text { of } \\
\text { Cycles }\end{array}$ & $\begin{array}{c}\text { Pozzolanic } \\
\text { CSH } \\
\text { Conversion }\end{array}$ & $\begin{array}{l}\text { Heat } \\
\text { Transfer } \\
\text { Mode }\end{array}$ & Curing & $\begin{array}{c}\text { Initial } \\
\text { Temperature }\end{array}$ \\
\hline Create Plot & $\begin{array}{l}\text { adiabatic heat signature } \\
\text { (adi) }\end{array}$ & 1600 & off & isothermal & saturated & 25 \\
\hline Create Plot & chemical shrinkage & 1600 & off & isothermal & saturated & 25 \\
\hline Create Plot & hydration & 1600 & off & isothermal & saturated & 25 \\
\hline Create Plot & heat release & 1600 & off & isothermal & saturated & 25 \\
\hline $\begin{array}{l}\text { Create Plot } \\
\text { Include data: } \\
\mathrm{X}\end{array}$ & $\begin{array}{l}\text { compressive strength } \\
\text { strength } \\
\text { prefactor } \\
95 \\
\mathrm{MPa}\end{array}$ & 1600 & off & isothermal & saturated & 25 \\
\hline
\end{tabular}

Figure 21: Example of results available for plotting via Menu Selection 17. 


\subsection{Menu Selection 18) Predict chloride ion diffusivity of a concrete based on mixture parameters}

The final menu selection of the VCCTL is provided to calculate an estimated chloride ion diffusion coefficient for a concrete (optionally containing silica fume), based on knowledge of its mixture proportions and the achieved degree of hydration. The equations used in this prediction have been presented previously [12] and are also incorporated into a prototype Computer Integrated Knowledge System (CIKS) for predicting the service life of steel-reinforced concrete exposed to chloride ions [13], available separately from the VCCTL. To use Menu Selection 18, the user supplies the following four inputs for the concrete of interest: the w/c ratio, the silica fume content (mass fraction of cement basis), the volume fraction of aggregates, and the degree of hydration of the cement. Recommended ranges of applicability for each of these parameters are provided on the fill-in form and the user should extrapolate beyond these ranges only with extreme caution. Upon submittal, the estimated value of the diffusion coefficient, D, in SI units, is returned along with the $90 \%$ confidence limits for D and some instructions on methodologies to lower the D value, if necessary. 


\section{Prediction of the Chloride Ion Diffusivity of a Concrete Based on Mixture Parameters}

\section{Please supply the following parameters (defaults provided)}

w/c ratio (water-to-cement ratio) ${ }_{0.40}$ (recommended range of 0.3 to 0.5 )

Silica fume addition (mass \% of cement) ${ }_{5.00}$ (recommended range of $0 \%$ to $10 \%$ )

Volume fraction of Aggregate $70.00 \%$ (recommended range of $62 \%$ to $70 \%$ )

Degree of Hydration of the Cement ${ }_{0.75}$ (recommended range of 0.6 to 0.9)

Submit form to estimate diffusivity

Reset all values to defaults

Papers on the modelling techniques used to estimate $\mathrm{D}$ are available online by clicking on the titles in the following references:

Bentz, D.P., Influence of Silica Fume on Diffusivity in Cement-Based Materials. II. Multi-Scale Modeling of Concrete Diffusivity, Cement and Concrete Research, 30 (7), 1121-1129, 2000.

Bentz, D.P., Detwiler, R.J., Garboczi, E.J., Halamickova, P., and Schwartz, L.M., Multi-Scale Modelling of the Diffusivity of Mortar and Concrete, RILEM International Conference on Chloride Penetration into Concrete, 1995.

Bentz, D.P., Garboczi, E.J., and Lagergren, E.S., Multi-Scale Microstructural Modeling of Concrete Diffusivity: Identification of Significant Variables, Cement, Concrete, and Aggregates, 20 (1), 129-139, 1998.

Click here to view the database of experimental diffusivities.

Figure 22: Form to specify inputs for predicting chloride ion diffusivity of a concrete based on mixture parameters. 


\section{Example Applications of the VCCTL}

\subsection{Replacement of Coarse Cement Particles by Inert Fillers}

In low w/c $(<0.38)$ concretes, hydration of the cement will be incomplete, as there is insufficient pore space within which the hydration products can deposit. Thus, in these concretes, a portion of the relatively expensive cement is potentially being wasted and serving only as a reinforcing filler material. Recently, the VCCTL has been applied to investigating the potential of replacing a portion of the coarser cement particles by inert fillers [7]. A few example results from this study will be presented here.

As a base case, the study considered a concrete with a w/c of 0.25 . All microstructures were based on the phase composition and PSD (provided in the cement images database) of Cement 135 issued by the Cement and Concrete Reference Laboratory in January of 2000, and previously characterized using the CEMHYD3D hydration model [6]. Initial microstructures were created with no cement replacement, and with the coarsest $20.5 \%$ and $30.8 \%$ of the cement particles (mass basis) replaced by an inert filler material. All three microstructures were created using Menu Selection 3 of the VCCTL. The inert particles were simply added by changing the phase ID for the appropriate larger diameter particles from cement to inert filler in the input table shown in Figure 7. Phases were then distributed amongst the cement particles in each system, according to the measured 2-D image values for Cement 135 [6], using Menu Selection 7. The resultant starting microstructures were then examined using Menu Selection 4, with representative 2-D slices being shown in Figures 23 and 24 for the systems with $0 \%$ and $30.8 \%$ cement replacement, respectively. 


\section{Slice 25 from cem135wc025f.img at $5 \mathrm{X}$ magnification}

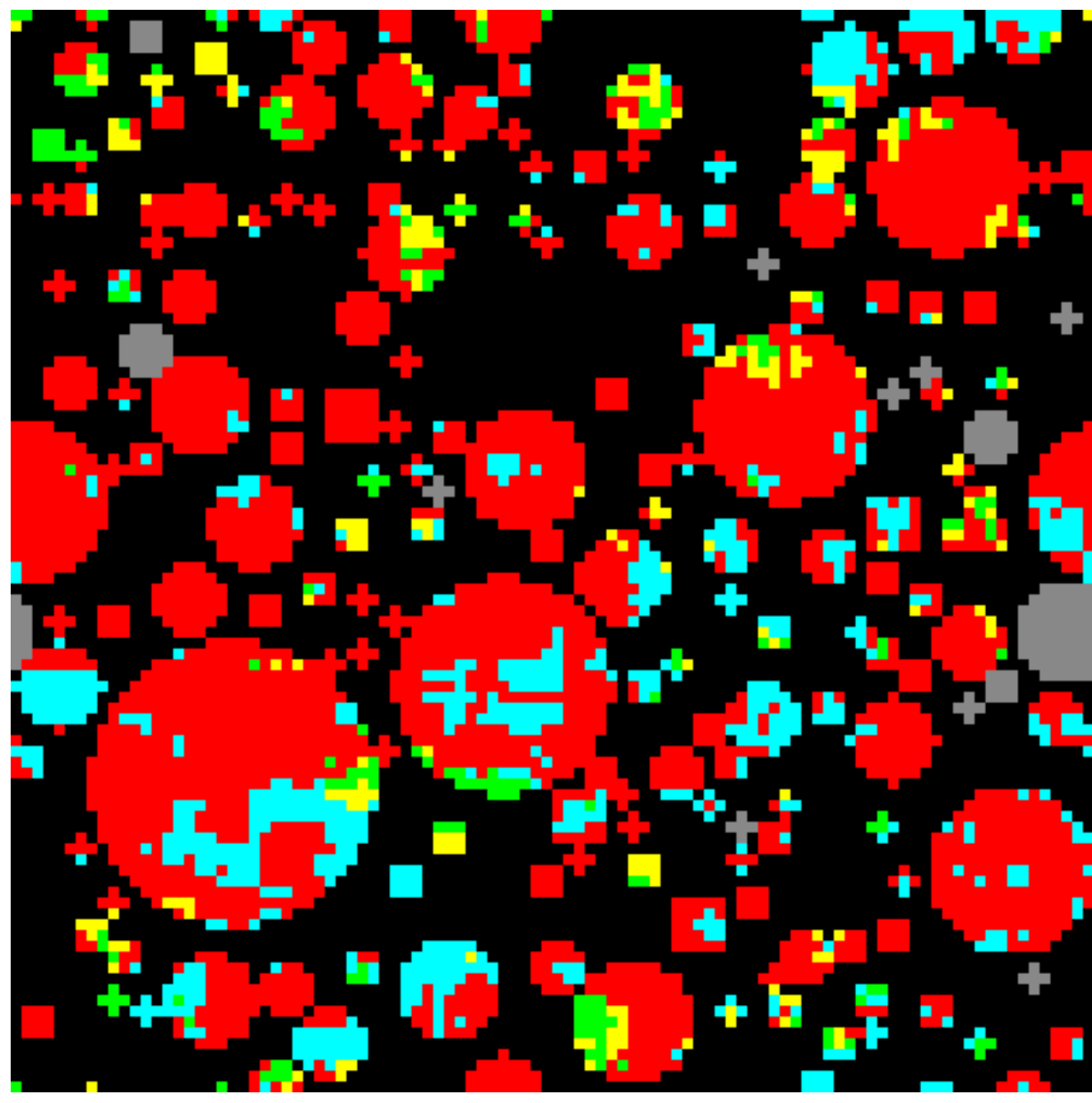

Black is water-filled porosity

$$
\text { Red is } \mathrm{C}_{3} \mathrm{~S} \text { (silicates) Aqua is } \mathrm{C}_{2} \mathrm{~S}
$$

Green is $\mathrm{C}_{3} \mathrm{~A} \quad$ Yellow is $\mathrm{C}_{4} \mathrm{AF}$ (aluminates)

Greys are hemihydrate, gypsum, and anhydrite

$$
\text { Orange is } \mathrm{C}-\mathrm{S}-\mathrm{H} \quad \text { Blue is } \mathrm{CH}
$$

Pale green is other hydration products and aluminosilicates

Magenta is aggregate White is empty porosity (and fly ash)

$$
\text { Blue-grey is inert filler }
$$

\section{Return to the main menu}

Figure 23: 2-D slice from 3-D starting microstructure for Cement $135, \mathrm{w} / \mathrm{c}=0.25$, with no cement replacement by inert fillers. 


\section{Slice 50 from c135wc025fil30f.img at 5X magnification}

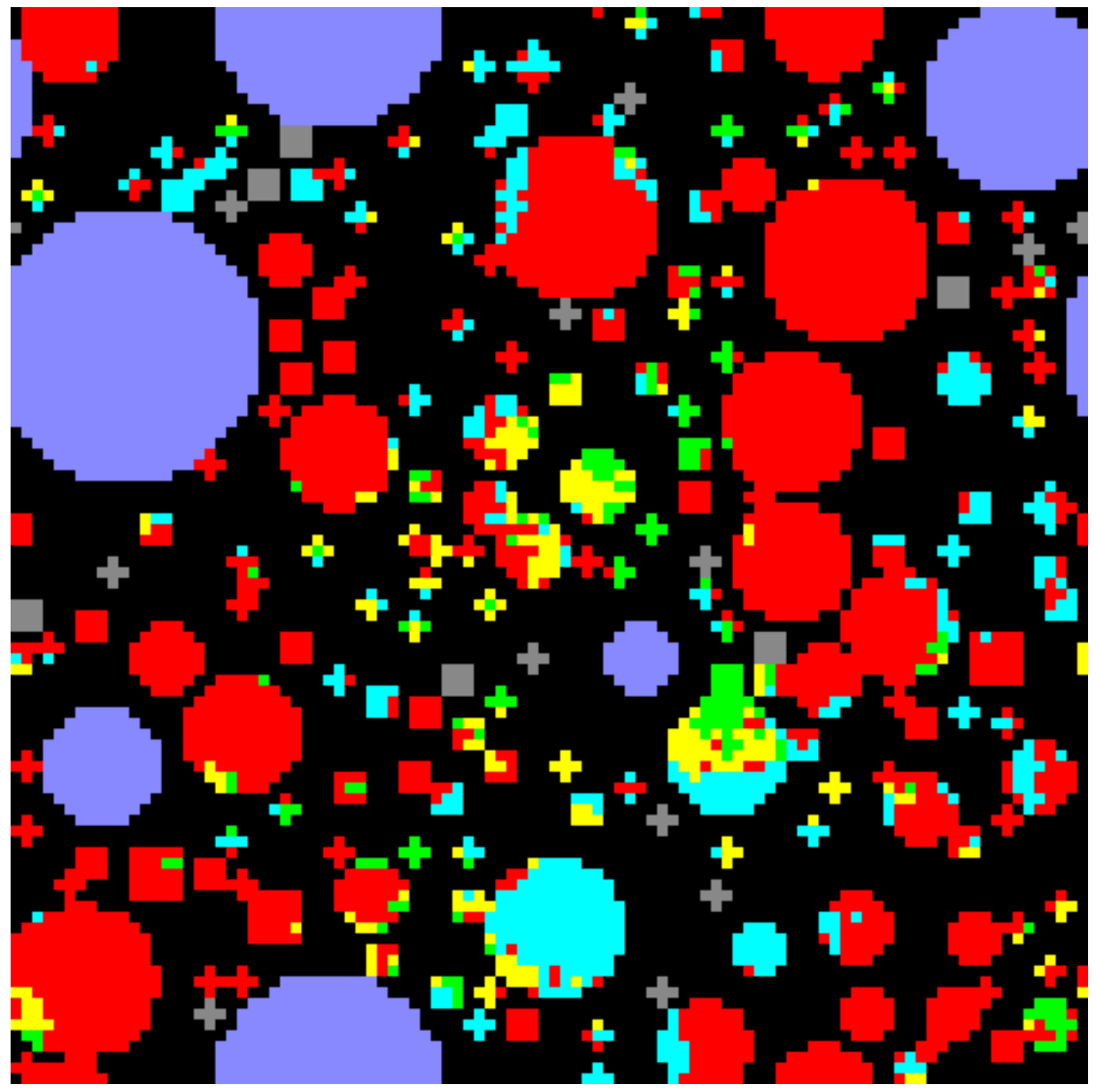

Black is water-filled porosity

Red is $\mathrm{C}_{3} \mathrm{~S}$ (silicates) Aqua is $\mathrm{C}_{2} \mathrm{~S}$

Green is $\mathrm{C}_{3} \mathrm{~A}$ Yellow is $\mathrm{C}_{4} \mathrm{AF}$ (aluminates)

Greys are hemihydrate, gypsum, and anhydrite

$$
\text { Orange is } \mathrm{C}-\mathrm{S}-\mathrm{H} \quad \mathrm{Blue} \text { is } \mathrm{CH}
$$

Pale green is other hydration products and aluminosilicates

Magenta is aggregate White is empty porosity (and fly ash)

Blue-grey is inert filler

\section{Return to the main menu}

Figure 24: 2-D slice from 3-D starting microstructure for Cement $135, \mathrm{w} / \mathrm{c}=0.25$, with $30.8 \%$ cement replacement by inert fillers. 
The systems were then hydrated for 4000 dissolution/reaction cycles [2], representing about $200 \mathrm{~d}$ of real hydration time under saturated/sealed conditions at $25^{\circ} \mathrm{C}$ [6], using Menu Selection 13. Saturated/sealed conditions indicate that the hydration is initially executed under saturated (water is imbibed into the 3-D microstructure) conditions, but the curing is switched to sealed curing (no further water imbibition) when the water-filled porosity depercolates during the hydration process. For this study, the percolation characteristics of the water-filled capillary porosity were evaluated after every 100 cycles of the hydration process. Representative images of 2-D slices after the hydration are provided in Figures 25 and 26. In the latter image, the hydrated microstructure is seen to be uniformly dense, even in the immediate vicinity of the inert filler particles, due to the low overall $\mathrm{w} / \mathrm{s}$ value. 


\section{Slice 25 from cem135wc025f.img.4000.25.000 at 5X magnification}

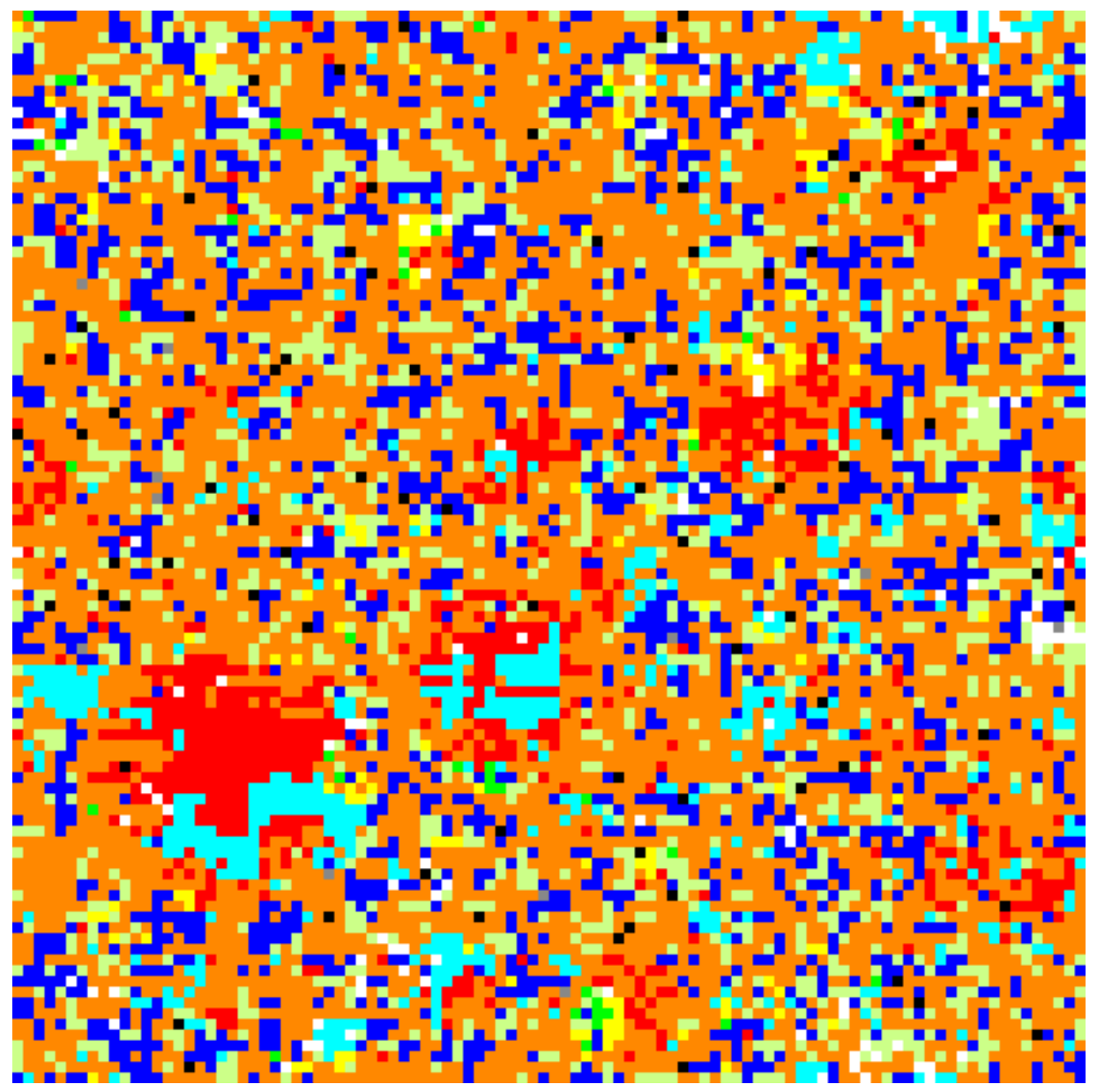

Black is water-filled porosity

$$
\begin{aligned}
& \text { Red is } \mathrm{C}_{3} \mathrm{~S} \text { (silicates) Aqua is } \mathrm{C}_{2} \mathrm{~S} \\
& \text { Green is } \mathrm{C}_{3} \mathrm{~A} \quad \text { Yellow is } \mathrm{C}_{4} \mathrm{AF} \text { (aluminates) } \\
& \text { Greys are hemihydrate, gypsum, and anhydrite }
\end{aligned}
$$

$$
\text { Orange is } \mathrm{C}-\mathrm{S}-\mathrm{H} \quad \text { Blue is } \mathrm{CH}
$$

Pale green is other hydration products and aluminosilicates

Magenta is aggregate White is empty porosity (and fly ash)

$$
\text { Blue-grey is inert filler }
$$

\section{Return to the main menu}

Figure 25: 2-D slice from 3-D hydrated microstructure for Cement 135, w/c=0.25, with no cement replacement by inert fillers. 


\section{Slice 50 from c135wc025fil30f.img.4000.25.000 at 5X magnification}

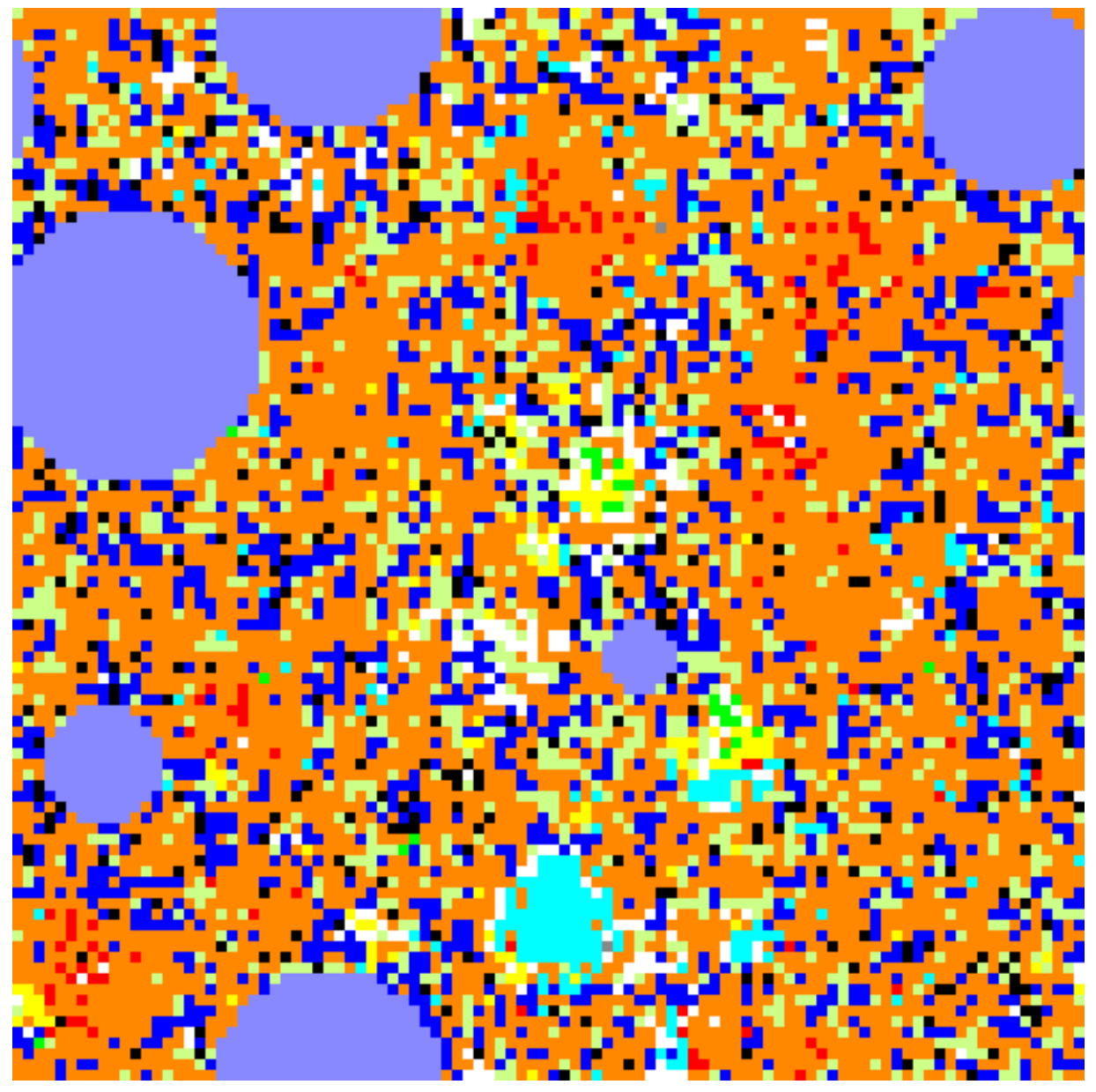

Black is water-filled porosity

$$
\begin{gathered}
\text { Red is } \mathrm{C}_{3} \mathrm{~S} \text { (silicates) Aqua is } \mathrm{C}_{2} \mathrm{~S} \\
\text { Green is } \mathrm{C}_{3} \mathrm{~A} \quad \text { Yellow is } \mathrm{C}_{4} \mathrm{AF} \text { (aluminates) } \\
\text { Greys are hemihydrate, gypsum, and anhydrite } \\
\text { Orange is } \mathrm{C}-\mathrm{S}-\mathrm{H} \quad \mathrm{Blue} \text { is } \mathrm{CH}
\end{gathered}
$$

Pale green is other hydration products and aluminosilicates

Magenta is aggregate White is empty porosity (and fly ash)

Blue-grey is inert filler

\section{Return to the main menu}

Figure 26: 2-D slice from 3-D hydrated microstructure for Cement 135 , w/c=0.25, with $30.8 \%$ cement replacement by inert fillers. 
The predicted degrees of hydration and compressive strength developments are compared amongst the three systems in Figures 27 and 28, which provide comparisons of the base system (no replacement) vs. the systems with $20.5 \%$ and $30.8 \%$ replacement, respectively. Compressive strengths for ASTM C109 [14] mortar cubes have been estimated using Power's gel-space ratio theory [11], assuming that the inert filler particles and unreacted cement cores contribute equally to the compressive strengths of the mortar cubes. The systems with the inert filler replacements are observed to attain larger degrees of hydration, due to their effectively higher w/c ratio. While they have less cement reacting overall, this increase in hydration rate results in a predicted compressive strength development that is inferior to but on the same order as the system with no cement replacement. The actual decreases in predicted compressive strengths are plotted in Figure 29. For both replacement levels, the difference in compressive strength is observed to reach a maximum after about $14 \mathrm{~d}$ and then decay towards zero. While the $>10 \mathrm{MPa}$ maximum predicted strength loss with the $30.8 \%$ replacement level might be deemed unacceptable, the $6 \mathrm{MPa}$ maximum loss with the $20.5 \%$ replacement level is most likely a reasonable tradeoff for the cost savings that would result from replacing relatively expensive cement by a hopefully inexpensive basically inert filler (such as limestone).
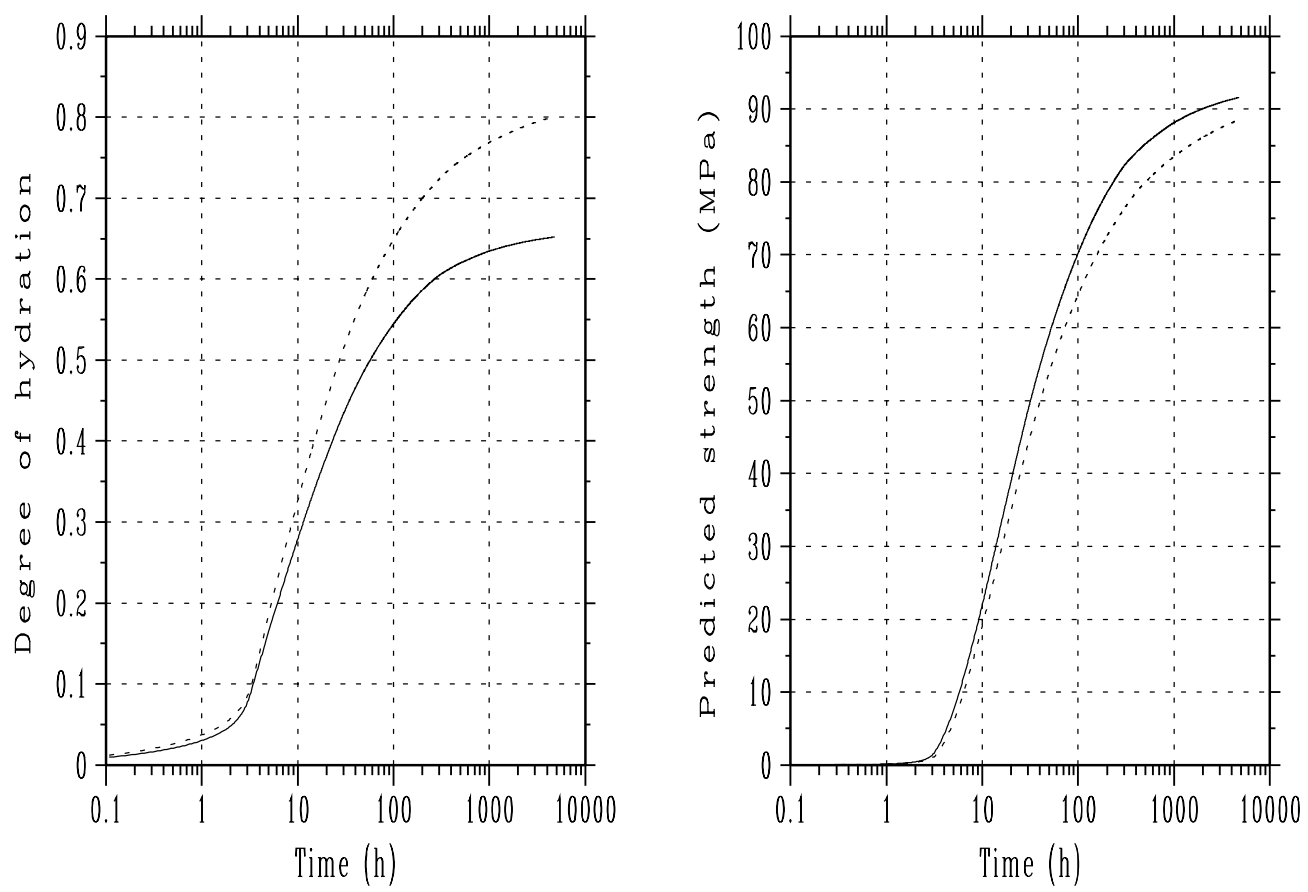

Figure 27: Predicted degree of hydration and compressive strength development for base $w / c=0.25$ system and system with coarsest $20.5 \%$ of cement particles replaced by inert filler. Solid line is original system and dotted line is system with $20.5 \%$ replacement. 

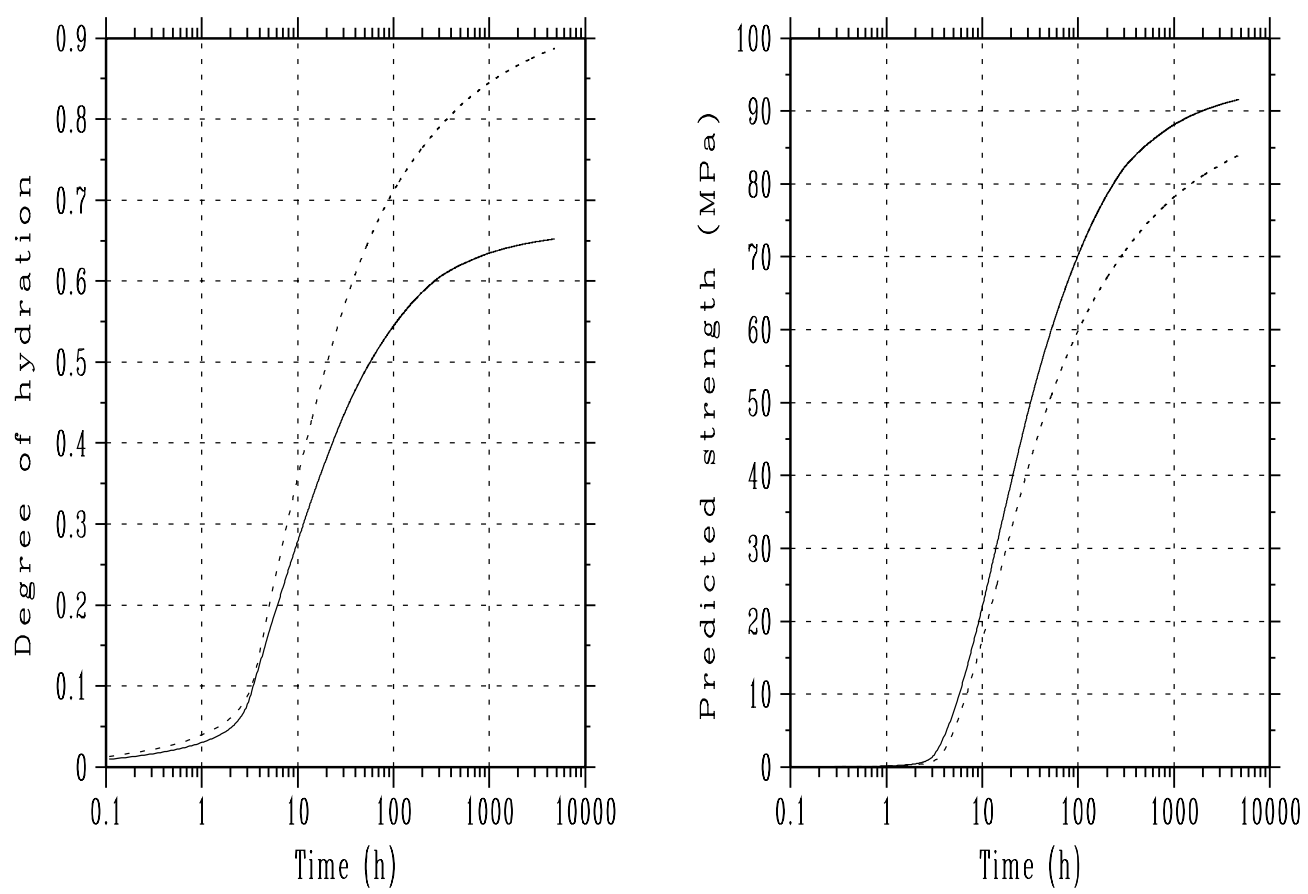

Figure 28: Predicted degree of hydration and compressive strength development for base $w / c=0.25$ system and system with coarsest $30.8 \%$ of cement particles replaced by inert filler. Solid line is original system and dotted line is system with $30.8 \%$ replacement. 


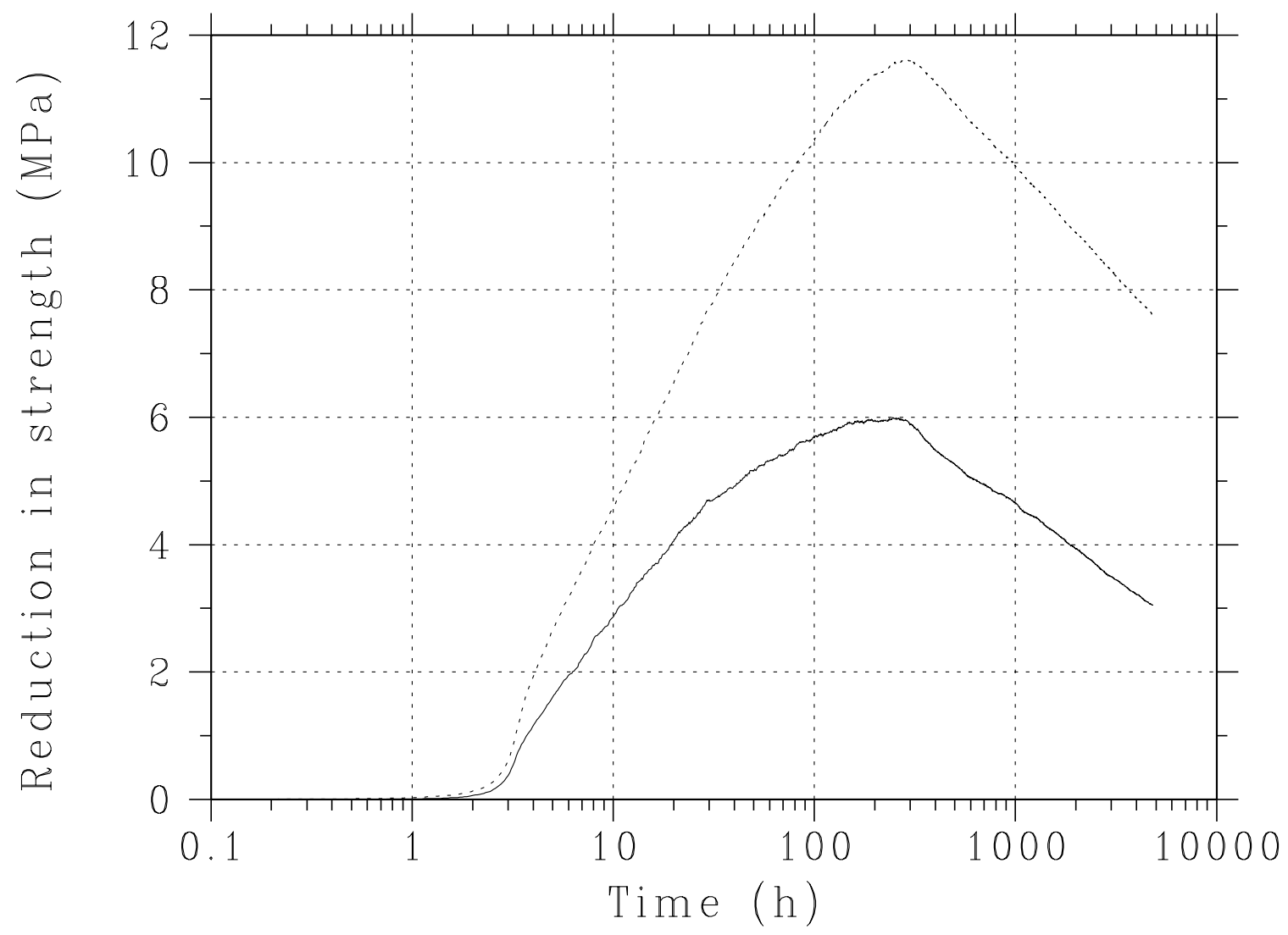

Figure 29: Predicted reduction in compressive strength due to coarse cement particle replacement for Cement 135 with $\mathrm{w} / \mathrm{s}=0.25$. Solid line is reduction with $20.5 \%$ replacement level and dotted line is reduction with replacement level of $30.8 \%$. 


\subsection{Seeding of the Hydration with Fine $C-S-H$ particles}

The VCCTL can also be used to explore unconventional means of modifying cement hydration kinetics and microstructure development. For example, the use of microfine $C-S-H$ particles to seed the hydration of cement has recently been investigated [15]. Here, a simple comparison can be made between the predicted hydration and strength development of systems with and without the $C-S-H$ seeding. Once again, Cement $135 \mathrm{is}$ used, this time with a w/c of 0.40 . The base system is compared to one with an addition of $0.0026 \mathrm{~g}$ $C-S-H / g$ cement, a very low addition rate. Specifically, this required the addition of only 1717 one-pixels particles of $C-S-H$ to the starting microstructure when specifying the input for Menu Selection 13, via the entry just beneath the "Inert filler" row in the middle of Figure 16. The phase ID used for $C-S-H$ is 13 , as indicated in the table in Figure 11.

Both systems were then hydrated under saturated/sealed conditions at $25^{\circ} \mathrm{C}$ for 1600 cycles (or about $32 \mathrm{~d}$ ) of hydration using Menu Selection 13. The predicted degrees of hydration and compressive strength developments are shown in Figure 30. Because the $C-S-H$ concentration affects the induction period in the CEMHYD3D model [1], addition of the $C S H$ seeds is seen to shorten the induction period and increase the predicted degrees of hydration and compressive strengths at all times. After 4 days, the projected increase in compressive strength due to the $C S H$ seeding is on the order of $5 \mathrm{MPa}$, while after 32 days it has decreased somewhat to about $3 \mathrm{MPa}$. Particularly, the hydration of the cement's silicate phases are increased by the seeding with microfine $C-S-H$ particles. After $32 \mathrm{~d}$, the degree of hydration of the $C_{3} S$ is increased from 0.8876 to 0.9088 , while that of the $C_{2} S$ is increased from 0.6198 to 0.6650 . These degrees of hydration of specific phases were easily determined by using Menu Selection 9 to compute the phase counts before and after hydration for each of the two systems. This simulation study is very preliminary in nature, but does suggest that the benefits of increasing silicate hydration by the addition of "seed" $C-S-H$ particles could be significant. 
Cement 135 original $\mathrm{w} / \mathrm{c}=0.40$

Solid line- original Dotted-C-S-H seeded
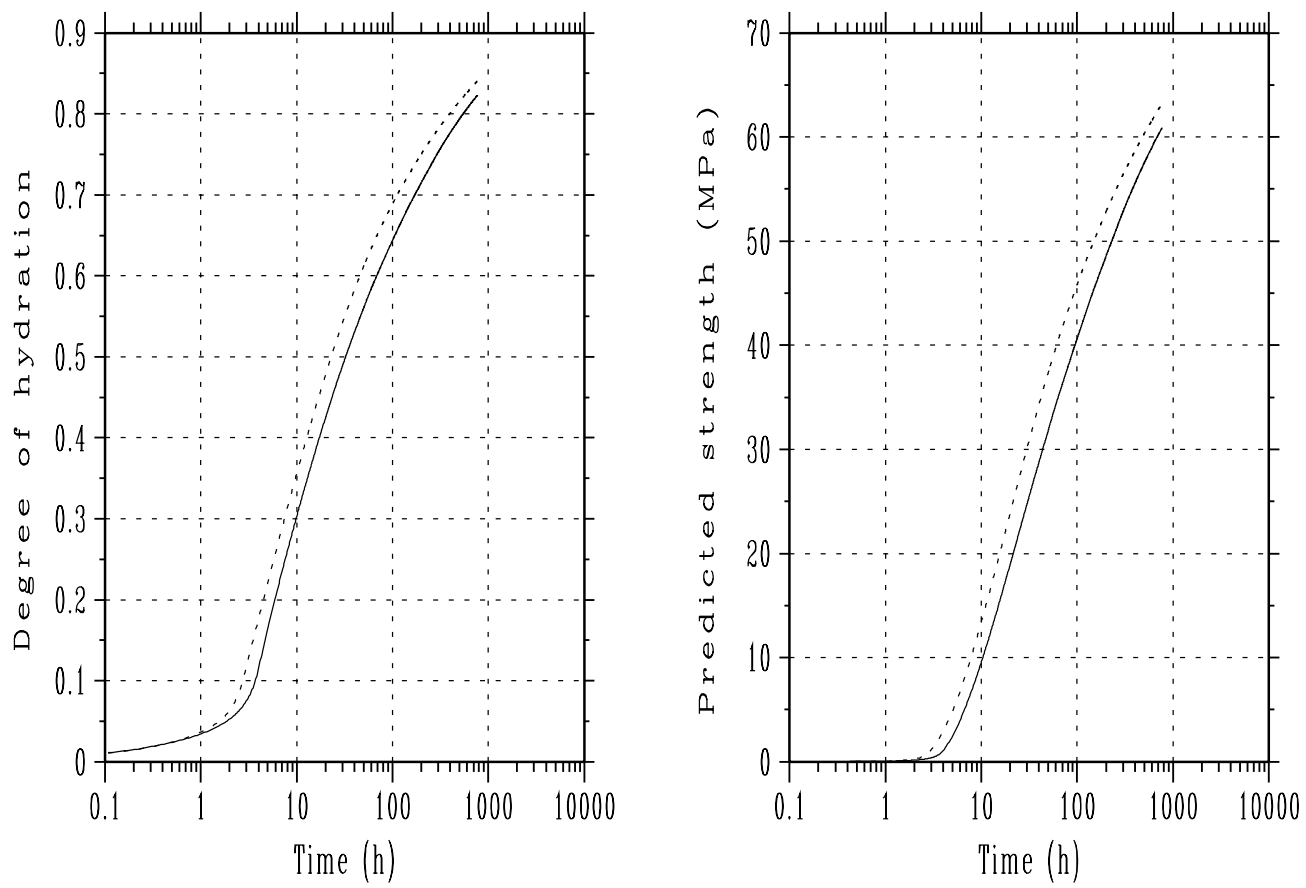

Figure 30: Predicted increase in hydration and compressive strength due to "seeding" microstructure with 1 $\mu \mathrm{m} C-S-H$ particles. 


\section{Summary}

A detailed description of the web-based menu-driven interface to Version 1.0 of the VCCTL has been provided. The interface consists of a series of fill-in HTML forms that allow the user to specify inputs for, and view results of, executing the various component programs of the VCCTL. Users are notified of the completion of program execution and in one case sent a copy of the analysis results by e-mail. The system has been designed to bring the VCCTL to the user's desktop computer, where their Internet browser provides them with a powerful connection to the world of virtual design, analysis, and optimization of cement-based materials.

The applications presented above hopefully provide a brief insight into the potential power of the VCCTL for conducting research and development of cement-based materials. The microstructure models underlying the VCCTL will continue to be enhanced and new features, such as the prediction of elastic and rheological properties, are currently under development.

\section{Acknowledgements}

The authors would like to acknowledge the NIST Partnership for High Performance Concrete Technology (PHPCT) program for funding this research and to thank Dr. Xiuping Feng, currently of Purdue University, for a detailed evaluation of an initial version of the Virtual Laboratory. 


\section{References}

[1] D.P. Bentz, "CEMHYD3D: A Three-Dimensional Cement Hydration and Microstructural Development Modelling Package. Version 2.0," NISTIR 6485, U.S. Department of Commerce, April 2000, available at http://ciks.cbt.nist.gov/monograph, Part I, Chapter 4, Section 2a.

[2] D.P. Bentz, Three-dimensional computer simulation of cement hydration and microstructure development, J Am Ceram Soc 80 (1) (1997) 3-21.

[3] D.P. Bentz and C.J. Haecker, An Argument for Using Coarse Cements in High Performance Concretes, Cem Concr Res 29 (1999) 615-618, available at http://ciks.cbt.nist.gov/monograph, Part I, Chapter 5, Section 8 .

[4] D.P. Bentz, E.J. Garboczi, C.J. Haecker, and O.M. Jensen, Effects of Cement Particle Size Distribution on Performance Properties of Cement-Based Materials, Cem Concr Res 29 (1999) 1663-1671, available at http://ciks.cbt.nist.gov/monograph, Part I, Chapter 5, Section 9.

[5] D.P. Bentz, O.M. Jensen, K.K. Hansen, J.F. Olesen, H. Stang, and C.J. Haecker, Influence of Cement Particle Size Distribution on Early Age Autogenous Strains and Stresses in Cement-Based Materials, accepted for publication in the Journal of the American Ceramic Society, 2000, available at http://ciks.cbt.nist.gov/monograph, Part I, Chapter 7, Section 13.

[6] D.P. Bentz, X. Feng, C.J. Haecker, and P.E. Stutzman, "Analysis of CCRL Proficiency Cements 135 and 136 Using CEMHYD3D," NISTIR 6545, U.S. Department of Commerce, August 2000, available at http://ciks.cbt.nist.gov/monograph, Part I, Chapter 4, Section 3.

[7] D.P. Bentz and J.T. Conway, Computer Modeling of the Replacement of "Coarse" Cement Particles by Inert Fillers in Low w/c Ratio Concretes: Hydration and Strength, submitted to Cement and Concrete Research, 2000.

[8] E.J. Garboczi, D.P. Bentz, K.A. Snyder, N.S. Martys, P.E. Stutzman, and C.F. Ferraris, Modelling and Measuring the Structure and Properties of Cement-Based Materials, U.S. Department of Commerce, online at http://ciks.cbt.nist.gov/monograph.

[9] D.P. Bentz, E.J. Garboczi, P.J.P. Pimienta, and W.C. Carter, Cellular Automaton Simulations of Surface Mass Transport Due to Curvature Gradients: Simulation of Sintering, in Synthesis and Processing of Ceramics: Scientific Issues, MRS Proceedings, Vol. 249, 413-418, 1992, available at http://ciks.cbt.nist.gov/monograph, Part II, Chapter 4, Section 2.

[10] D.P. Bentz and S. Remond, "Incorporation of Fly Ash into a 3-D Cement Hydration Microstructure Model," NISTIR 6050, U.S. Department of Commerce, August 1997, available at http://ciks.cbt.nist.gov/monograph, Part I, Chapter 4, Section $2 \mathrm{~b}$.

[11] H.F.W. Taylor Cement Chemistry, (Thomas Telford, London, 1997).

[12] D.P. Bentz, Influence of Silica Fume on Diffusivity in Cement-Based Materials. II. MultiScale Modeling of Concrete Diffusivity, Cem Concr Res 30 (7) (2000) 1121-1129, available at http://ciks.cbt.nist.gov/monograph, Part I, Chapter 7, Section 3a.

[13] D.P. Bentz, J.R. Clifton, and K.A. Snyder, A Prototype Computer-Integrated Knowledge System: Predicting Service Life of Chloride-Exposed Steel-Reinforced Concrete, Concr International, 18 (12), 42-47, Dec. 1996, CIKS software available online at http://ciks.cbt.nist.gov/bentz/welcome.html.

[14] ASTM Annual Book of Standards, Vol. 04.01 Cement; Lime; Gypsum (American Society for Testing and Materials, West Conshohocken, PA) 1999.

[15] B. Scheetz, private communication, August, 2000. 